\title{
EL FIN DE LA CONSCRIPCIÓN EN EUROPA: UN ESCENARIO DE OPCIONES SINGULARES
}

\author{
Rafael Ajangiz
}

Universidad del País Vasco

\begin{abstract}
RESUMEN
Se analizan los últimos cambios habidos en Europa en relación con el servicio militar obligatorio a partir de la constatación de un largo y amplio proceso de declive de los ejércitos de masas. Se presentan y analizan diez indicadores de esa crisis para llegar a la conclusión de que la sociedad civil, aquí llamada razón democrática, ha ejercido un influjo mucho mayor del que habitualmente se le reconoce en la reciente decisión de varios gobiernos europeos de suprimir tal obligación. En la mayoría de los casos estudiados, aun a pesar de que los gobiernos han sabido pautar este cambio en función de sus prioridades estratégicas, el fin de la conscripción es en realidad una consecuencia aplazada de la movilización de esa razón democrática. En otros, el caso de Italia y, muy especialmente, España, esa movilización ha forzado un apresurado y problemático cambio de los planes gubernamentales al respecto. Por fin, la continuidad de esta prestación en algunos países de nuestro entorno permite entender el fin de la conscripción como una decisión facultativa y no una consecuencia obligada de la elección o consolidación del modelo de empleo en las fuerzas armadas.
\end{abstract}

En muy pocos años, el mapa de la conscripción en Europa ha cambiado radicalmente: Bélgica decidió el fin del servicio militar obligatorio en el año 1992, Holanda en 1993, Francia y España lo hicieron en 1996, Italia en septiembre de 1999, Portugal está en ello, Alemania y Austria lo están debatiendo, Dinamarca y Suecia podrían sumarse en un futuro no muy lejano... La cuenta atrás está en marcha, o, al menos, eso parece. De los quince países que

\section{Reis}


componen la Unión Europea, doce contaban con reclutamiento forzoso hace ahora diez años; hoy han pasado a ser ocho, y podrían no ser más de cuatro en los próximos diez años ${ }^{1}$. Con todo, ¿es verdad que tocan a su fin los días del servicio militar obligatorio? ¿Podemos hablar de una pauta común? Y, en todo caso, ¿qué razones básicas explican los cambios habidos en el ámbito de esta política pública?

\section{LA CRISIS DEL RECLUTAMIENTO FORZOSO}

Reconocer que el reclutamiento forzoso ha entrado en crisis, una crisis muy grave, es el punto de partida imprescindible para encontrar respuesta a estas o parecidas preguntas. La globalización o el fin de la guerra fría son las referencias habituales en las explicaciones políticas actuales de esta crisis. Conceptos como el tránsito desde un mundo dominado por los Estados a un mundo policéntrico (Rosenau, 1994) o la llegada de tiempos nuevos (Dandeker, 1994b) hacen referencia a dos circunstancias que afectan directamente al papel y la configuración que se exige de las fuerzas armadas en este cambio de siglo: a) la crisis del Estado-nación, que afecta innegablemente a la definición nacional de las fuerzas armadas y, con ello, a la idea misma de la conscripción; y b) un nuevo escenario geoestratégico para la mayoría de los países europeos que resta mucha fuerza al que hasta ahora ha sido el argumento básico para legitimar la existencia de las fuerzas armadas, la defensa del territorio nacional ${ }^{2}$. El nuevo concepto estratégico de la Alianza Atlántica es la respuesta ad hoc a ese nuevo escenario; en él, la tradicional amenaza a la integridad territorial de los Estados miembros es reemplazada por esa señalada causa de inseguridad que es el riesgo imprevisible $e^{3}$ La política resultante consiste básicamente en la formación de fuerzas multinacionales cuya misión principal son las operaciones fuera de área; las intervenciones en el Golfo Pérsico, en África o en los Balcanes -esta última no se considera formalmente como fuera de área- serían sus ejemplos (Burk, 1994; Carr e Ifantis, 1996; Dorman y Treacher, 1995). Esta política supone, de hecho, una transferencia de autoridad a las instancias regionales en

1 Ver Thuysbaert (1994) para una presentación más detallada de las circunstancias que han rodeado la decisión de abolir la conscripción en Bélgica; Doel (1994) y Meulen y Manigart (1997) en el caso de Holanda; McKenna (1997) y Buffotot (1997c) en el de Francia, y Ajangiz (2000) con relación a España e Italia. La situación alemana se describe en ManfrassSirjacques (1997), la portuguesa en Buffotot (1997a), y en Sørensen (2000) la de los países escandinavos.

${ }^{2}$ En la actualidad, la opinión pública prefiere que sea la Unión Europea y no los gobiernos nacionales quien tome las decisiones en las políticas de seguridad y defensa y de relaciones exteriores (Manigart y Marlier, 1994).

${ }^{3}$ El nuevo concepto estratégico fue formulado por primera vez en la cumbre de la OTAN de Roma, en noviembre de 1991, y ha sido convalidado en reiteradas ocasiones; por ejemplo, la cumbre de Washington de 1999. 
detrimento de los gobiernos nacionales y contribuye a la crisis de sus modelos tradicionales de defensa.

Sin embargo, aunque la agraven considerablemente, el fin de la guerra fría y del subsiguiente cambio en el escenario estratégico no constituyen el arranque de la crisis de la conscripción. A principios de los setenta, Janowitz (Janowitz, 1972; Janowitz y Moskos, 1979) y Doorn $(1975,1976)$ diagnosticaron el declive de los ejércitos de masas al constatar que las dificultades que por aquel entonces experimentaba la conscripción eran estructurales y no un producto de la coyuntura bélica del momento ${ }^{4}$. En opinión de estos autores, eran cuatro los cambios estructurales, de carácter estratégico pero también social, que explicaban el declive de los ejércitos de masas: a) la nuclearización y tecnologización de la defensa; b) la intervención militar en terceros países; c) el cambio de valores y prioridades de las sociedades postmodernas, y d) la crisis de legitimidad social del servicio militar obligatorio.

Al hilo de este análisis, tan sugerente hoy como entonces, conviene llamar la atención sobre la dimensión social de la crisis de la conscripción, que es, cuando menos, tan importante como su dimensión estratégico-militar. Las movilizaciones en contra de la guerra de Vietnam son un ejemplo sobradamente conocido del rechazo que suscitaba el reclutamiento hace ahora nada menos que cuarenta años. No fue sólo el caso de Estados Unidos; países como Dinamarca, Noruega, Holanda y Alemania conocieron entonces un incremento sin precedentes de la objeción de conciencia, y en Francia, Italia y España se iniciaron campañas de desobediencia civil para que se reconociera formalmente esta alternativa al servicio militar (Mellors y McKean, 1982).

Aquellas movilizaciones tuvieron su impacto. Estados Unidos abolió la conscripción en aquel momento. Existen diferentes valoraciones al respecto, pero no resulta difícil pensar con Janowitz (1971) que la mayor responsabilidad de aquella abolición debe atribuirse a la movilización. En el caso de Dinamarca, las autoridades se decidieron por un sistema de reclutamiento selectivo para mitigar la crisis y, lo que no es demasiado conocido, los dirigentes de algunos países europeos, Francia, Bélgica y Holanda entre ellos, encargaron estudios técnicos para valorar la posibilidad de poner fin al servicio militar obligatorio. No llegaron a hacerlo, pero para garantizar su continuidad se vieron obligados a implementar enérgicas medidas contra aquella explosión de protesta, así como mecanismos penalizadores de la objeción de conciencia a más largo plazo (Kelleher, 1978; Martin, 1977; Mellors y McKean, 1984; Meulen y Manigart, 1997).

El paso del tiempo ha venido a confirmar que aquella crisis social de la

${ }^{4}$ Más aún, este análisis estaba ya presente en la obra El soldado profesional, que Janowitz publicara en 1960 y que no ha sido traducida al castellano hasta 1990 (Janowitz, 1990), así como en sus otras obras de esa década. Janowitz, figura clave en la sociología militar, fue el promotor del influyente Seminar on Armed Forces and Society y de su conocida revista Armed Forces and Society, que vio la luz en 1975 con un monográfico justamente sobre el declive de los ejércitos de masas. 
conscripción no fue producto de una coyuntura determinada. El gran incremento de las cifras de objeción de conciencia en Alemania, España e Italia, por ejemplo, sigue contradiciendo esa arraigada legitimidad social del servicio en armas que nuestros gobernantes siempre han tenido como cierta. Resulta difícil creer que ahora los jóvenes eligen la objeción de conciencia porque son conscientes de que, de diez años a esta parte, han dejado de ser necesarios para la defensa territorial y sirven mejor a su país apuntalando el Estado de bienestar. Más razonable es pensar que durante todo este tiempo han ingresado en las fuerzas armadas no por convicción, sino por conveniencia, bien porque no existía alternativa alguna o bien porque era una alternativa insegura o desproporcionalmente penalizada en relación con el servicio militar. Dadas las circunstancias, la mili era el mal menor.

En efecto, todos los datos avalan la existencia de un más o menos profundo descontento social en relación con el reclutamiento forzoso, que, además, se extiende por todo el planeta. De ahí que existan protestas y resistencia al reclutamiento en contextos culturales y sociopolíticos muy variados. Por poner algunos ejemplos, esta resistencia social ha motivado la abolición de la conscripción en Sudáfrica en 1991, en Argentina en 1994 y en España en 1996, y su reducción a la mitad en Chile en 1994, lo mismo que en Vietnam, Corea del Sur o Taiwan; la presentación en Brasil de mociones parlamentarias exigiendo su eliminación coincide con una progresiva implantación de la objeción de conciencia en otros países de América Latina como Paraguay, Guatemala o Colombia; la gran mayoría de los conscriptos eluden el reclutamiento en Rusia, son muchos los griegos exiliados en Europa por la misma razón, y en Israel los reclutas optan masivamente por los servicios sin armas 5 .

En suma, dos son las ideas-fuerza que vertebran este artículo. La primera, que la crisis de la conscripción no es reciente: era visible hace cuarenta años y durante todo este tiempo no ha hecho sino profundizarse. De hecho, sería más propio concebirla como una crisis estructural, macro, que afecta a todos los países más o menos por igual. Y la segunda, que las fuerzas sociales han ejercido mucha mayor influencia en la definición de esta política militar que la que normalmente se admite.

Para contrastar estas ideas, vamos a examinar a continuación los valores de diez variables que en la literatura al caso se proponen como relevantes: a) la evolución del gasto militar; b) el volumen de las fuerzas armadas nacionales en relación con el tamaño poblacional; c) la nuclearización y/o mejoras tecnológicas de las fuerzas armadas; d) la resistencia al reclutamiento, más concretamente la objeción de conciencia; e) la posición de la opinión pública en relación con la conscripción; f) la posición de la opinión pública en relación con el envío de reclutas forzosos a intervenciones en otros países; $g$ ) el desarrollo de

5 Para una compilación actualizada del hecho conscriptivo, ver Horeman y Stolwijk (1998) y Horeman et al. (1997). Referencias sobre movilizaciones de protesta, en Ajangiz (2000). 
las fuerzas de acción rápida o inmediata; h) la proporción entre conscriptos y personal voluntario; i) el input de conscriptos en las fuerzas armadas, y $j$ ) el input de personal remunerado. El análisis de estas diez variables nos permitirá apreciar cuáles han sido los factores determinantes en la supresión o continuidad del servicio militar obligatorio en cada uno de los diez países europeos analizados.

\section{GASTO MILITAR, TAMAÑO Y TECNOLOGIZACIÓN DE LAS FUERZAS ARMADAS}

La sustitución de reclutas forzosos por soldados remunerados y por un equipamiento más sofisticado hace que toda transición hacia unas fuerzas armadas sin servicio militar obligatorio - all-volunteer force- suponga un esfuerzo extraordinario en términos presupuestarios; la experiencia de Estados Unidos es suficientemente ilustrativa al respecto (Janowitz y Moskos, 1979). Por consiguiente, contar con un historial de gasto militar elevado mejora notablemente las posibilidades de una transición ordenada; operaría como una especie de capital acumulado o de inversión suficiente a tal efecto. Además, el comportamiento de este índice en la última década nos indicará si los gobiernos han asignado recursos extraordinarios para asegurar la defensa ante una eventual supresión de la conscripción.

\section{TABLA 1}

Gasto militar en las últimas décadas

\begin{tabular}{|c|c|c|c|c|c|c|c|c|c|c|}
\hline & $R U$ & Fra. & Por. & Nor. & Hol. & Ale. & Bél. & Ita. & Din. & Esp. \\
\hline Gasto militar medio $1970-1998 \ldots \ldots \ldots$ & 4,2 & 3,8 & 3,6 & 2,9 & 2,9 & 2,9 & 2,7 & 2,2 & 2,2 & 1,9 \\
\hline Gasto militar en 1998 (\% PIB) ......... & 2,6 & 2,8 & 2,4 & 2,1 & 1,8 & 1,5 & 1,5 & 1,7 & 1,6 & 1,3 \\
\hline Valor asignado en la matriz final ........ & ++ & ++ & ++ & + & + & + & + & & & \\
\hline
\end{tabular}

FuENTES: The Military Balance, Londres: The International Institute for Strategic Studies \& Oxford University Press; World Development Indicators, Washington: World Bank; SIPRI Yearbook of World Armaments and Disarmament, Stockholm: Stockholm Peace Research Institute, y Oxford: Oxford University Press; Statistics from NATO, página web de la OTAN.

Al principio de la década de los noventa, al menos en lo que a gasto militar se refiere, Francia, Portugal, Noruega, Holanda, Alemania y Bélgica, precisamente por haber cumplido con el criterio del 3\% del PNB durante la guerra fría, estaban en mejores condiciones para suprimir la conscripción que, por 
ejemplo, Italia, Dinamarca o España. En 1987-88, todos procedieron a reducir el gasto militar, intentando compensar esa menor cantidad con una mayor calidad. Value for money ha sido desde entonces la frase más repetida en todos los Departamentos de Defensa europeos (Dandeker, 1994a), generando un dividendo de la paz que en gran parte ha sido empleado para sufragar la crisis de los ochenta y las exigencias de la convergencia monetaria. Para aquellos países con menos inversión previa, sin embargo, esta reducción generalizada del gasto militar se convirtió en una buena oportunidad para acomodar gradualmente las estructuras de sus fuerzas armadas al perfil medio europeo y reducir así las distancias históricas.

Los datos confirman que cada país ha tomado sus propias decisiones en esta última década. Alemania, más preocupada por la reunificación y el peso económico que puede llegar a disfrutar en el nuevo escenario europeo que por el poder militar, ha reducido su gasto militar hasta en un 54\%. Conservar la conscripción en sus dos modalidades, militar y civil, aun a pesar de una creciente oposición, ha contribuido a contener el gasto público. Paradójicamente, la decisión de suprimir el reclutamiento forzoso ha posibilitado los ahorros de Bélgica (53\%) y Holanda (43\%); podría incluso decirse que, en el caso de Bélgica, las dificultades para cumplir con los requisitos de la moneda única son, en buena medida, las que han dictado el fin del servicio militar obligatorio. En cambio, el menor ahorro de Dinamarca (32\%), Noruega (31\%), Francia (30\%), Portugal $(27 \%)$ e Italia $(24 \%)$ permite deducir que las políticas militares han ocupado un puesto más alto en la lista de prioridades que en los otros países. Este menor ahorro avalaría la apuesta de Francia, Portugal e Italia por unas fuerzas armadas de reclutamiento voluntario.

En este contexto, la evolución de España es ciertamente singular. Al igual que Francia, Italia y Portugal, hemos optado por unas fuerzas armadas sin servicio militar obligatorio, una transformación estructural tremendamente compleja y exigente en nuestro caso, pero, a diferencia de esos países, además de contar con uno de los gastos militares históricamente más modestos de Europa, España se ha significado en la última década como uno de los países que más ha ahorrado en este concepto, un $45 \%$. Esta contradicción, que actúa como un verdadero lastre en la ejecución de esta política pública, permite pensar que ha sido la sociedad civil quien ha decidido la supresión de la conscripción en nuestro país y no tanto la previsión, planificación o liderazgo de los responsables políticos y militares.

En efecto, los dos partidos mayoritarios materializaron hace diez años un acuerdo por el cual se comprometían a incrementar el gasto militar hasta la cota del $2 \%$ del PNB, y ello precisamente para asegurar la modernización de las fuerzas armadas y la intensificación a largo plazo de su componente voluntario. La tendencia real, sin embargo, operaba en sentido inverso. En 1996, el nuevo gobierno popular comunicó que incrementar significativamente el gasto militar era condición necesaria para llevar a buen puerto la importante reestructuración militar que implicaba la abolición de la conscripción. Sin embar- 
go, su política real desde entonces ha sido el crecimiento cero, lo que en la práctica está significando un progresivo alejamiento de aquel objetivo tan básico. Así, en el año 2000 el gasto militar español ha supuesto el 1,3\% del PNB. Cosidó (1994, 1996), asesor gubernamental y especialista en esta materia, ha argumentado que esta contención tiene una explicación genuinamente democrática: como quiera que gasto militar y gasto social han tenido siempre una relación de sustitución recíproca, cualquier aumento del gasto militar devendría en una reducción del gasto social que la sociedad española no está dispuesta a convalidar.

\section{TABLA 2}

Evolución del gasto militar y del volumen total de efectivos entre los años ochenta (media) y 1998 (en porcentajes)

\begin{tabular}{llllllllllllll}
\hline & Bél. & Ale. & Hol. & Esp. & Por. & RU & Fra. Din. Ita. & Nor. \\
\cline { 2 - 8 } \\
Gasto militar ...................................................... & -53 & -54 & -43 & -45 & -27 & -47 & -30 & -32 & -24 & -31 \\
Volumen de efectivos ....................... & -53 & -50 & -45 & -42 & -38 & -35 & -27 & -20 & -23 & -22 \\
\hline
\end{tabular}

FuENTES para el volumen de efectivos: The Military Balance, Londres: The International Institute for Strategic Studies \& Oxford University Press; Patrice Buffotot (ed.), La défense en Europe. París: La Documentation Française; Libros Blancos de Bélgica, Grecia y el Reino Unido; Projet le Loi relatif à la programmation militaire pour les années 1997 à 2002, Assemblée National, 7-6-1996 (Francia); Nuevo Modelo de Fuerzas Armadas, Ministerio de Defensa, 5-12-1996 (España); páginas web de los Ministerios de Defensa de Dinamarca, Francia, Alemania, Noruega, Reino Unido, Italia, Holanda y España.

El tamaño de las fuerzas armadas europeas sigue un patrón evolutivo muy parecido al del gasto militar. En los últimos veinte años, pero de forma más acentuada a partir de 1988, se ha reducido notablemente el volumen de personal militar en toda Europa. En su conjunto, las fuerzas armadas son ahora un tercio más pequeñas que hace dos décadas. Esta trayectoria podría explicarse como una consecuencia del fin de la guerra fría. De hecho, el tamaño de las fuerzas armadas ha variado constantemente a lo largo del siglo XX como consecuencia de las variaciones en el reclutamiento que han dictado los ciclos de guerra y paz. Sin embargo, el empequeñecimiento de la última década no hace sino continuar con una tendencia que se inició bastante antes del fin de la guerra fría, concretamente en los años sesenta y setenta, período en el cual se impulsaron importantes cambios estructurales en bastantes fuerzas armadas europeas. 


\section{TABLA 3}

Evolución de las fuerzas armadas europeas por categoría de tamaño

\begin{tabular}{|c|c|c|c|c|}
\hline & 1980 & 1989 & 1998 & 2002 \\
\hline 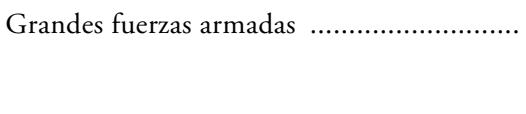 & $\begin{array}{l}\text { Alemania }(654.000) \\
\text { Turquía }(570.000) \\
\text { Francia }(500.000)\end{array}$ & $\begin{array}{l}\text { Alemania }(659.000) \\
\text { Turquía }(651.000) \\
\text { Francia }(466.000)\end{array}$ & Turquía (640.000) & Turquía \\
\hline 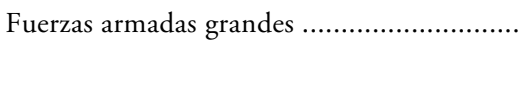 & $\begin{array}{l}\text { Italia }(370.000) \\
\text { España }(340.000) \\
\text { R. Unido }(325.000)\end{array}$ & $\begin{array}{l}\text { Italia }(390.000) \\
\text { R. Unido }(312.000)\end{array}$ & $\begin{array}{l}\text { Alemania }(330.000) \\
\text { Francia }(360.000)\end{array}$ & Alemania (320.000) \\
\hline Fuerzas armadas medianas $(1) \quad \ldots \ldots \ldots \ldots \ldots . . . . . . .$. & & $\begin{array}{l}\text { España }(285.000) \\
\text { Grecia }(208.000)\end{array}$ & $\begin{array}{l}\text { Italia }(290.000) \\
\text { R. Unido }(215.000)\end{array}$ & $\begin{array}{l}\text { Francia }(250.000) \\
\text { R. Unido }(225.000)\end{array}$ \\
\hline 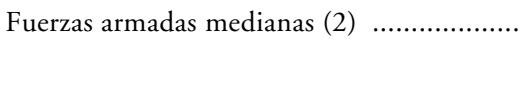 & Grecia (190.000) & & $\begin{array}{l}\text { España }(185.000) \\
\text { Grecia }(150.000)\end{array}$ & $\begin{array}{l}\text { Italia }(200.000) \\
\text { Grecia }(140.000) \\
\text { España }(123.000)\end{array}$ \\
\hline 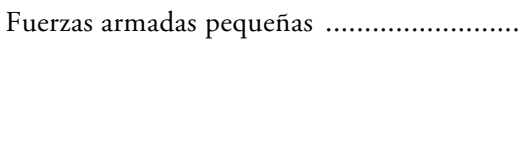 & $\begin{array}{l}\text { Holanda }(100.000) \\
\text { Bélgica }(90.000) \\
\text { Portugal }(70.000) \\
\text { Noruega }(38.000) \\
\text { Dinamarca }(32.000)\end{array}$ & $\begin{array}{l}\text { Holanda }(100.000) \\
\text { Bélgica }(92.000) \\
\text { Portugal }(75.000) \\
\text { Noruega }(34.000) \\
\text { Dinamarca }(32.000)\end{array}$ & $\begin{array}{l}\text { Holanda }(57.000) \\
\text { Bélgica }(45.000) \\
\text { Portugal }(43.000) \\
\text { Noruega }(29.000) \\
\text { Dinamarca }(24.000)\end{array}$ & $\begin{array}{l}\text { Holanda }(60.000) \\
\text { Bélgica }(40.000) \\
\text { Portugal }(38.000) \\
\text { Noruega }(29.000) \\
\text { Dinamarca }(23.000)\end{array}$ \\
\hline
\end{tabular}


En cualquier caso, lo cierto es que en los últimos veinte años se ha producido una transformación sustancial del mapa militar europeo. Al principio de los ochenta, si excluimos a Turquía, existían cinco grandes fuerzas armadas en Europa: Alemania, Francia, el Reino Unido, Italia y España, flanqueadas a bastante distancia por un nutrido grupo de fuerzas menores. Hoy, si bien siguen destacando las fuerzas de Alemania, Francia y el Reino Unido, podríamos concluir que, en general, existen menores diferencias que antaño. Este acercamiento agranda la importancia de otros factores, como el equipamiento, la formación, la operatividad o el papel que juegan en el nuevo diseño europeo. Por ejemplo, Francia y el Reino Unido mejoran la capacidad militar de Alemania, y ejércitos como los de Holanda y Bélgica, más pequeños que el español, además de estar mejor equipados humana y materialmente, han mejorado su posición relativa, ubicándose en el centro operativo del nuevo espacio militar europeo.

Así pues, los operativos de España o Italia, que además deberán competir con nuevas incorporaciones que operan prácticamente en el mismo segmento de fuerza, como es el caso de Polonia, han perdido mucho peso en el escenario europeo de defensa y seguridad, y ello a pesar de la ambición de sus gobernantes. La fuerza prevista por socialistas y populares desde que pactaron el modelo Fuerzas Armadas 2000 en 1991 hasta enero de 1999 fue de 180.000 efectivos. Hoy, con un volumen real que no llega a 125.000 , los nuevos planes de 150.000 efectivos parecen más bien una concesión a la realidad social. Italia podría verse en una situación parecida: la reforma prevé 190.000 efectivos en la segunda década del 2000, pero la progresión del déficit de reclutas anticipa una cota bastante menos ambiciosa.

Las causas de esta reducción son sociales antes que políticas. La evolución del número de efectivos militares está determinada por cinco grandes factores: a) las decisiones internacionales de desarme; $b$ ) las decisiones nacionales de reestructuración o ajuste de fuerza; c) la abolición o cambio en la duración del servicio militar obligatorio; d) la evolución natural de la población reclutable, $y$, en último lugar, e) el volumen de la población reclutada. El impacto que tiene cada uno de estos factores varía en función del país, pero, en general, hemos apreciado: 1) que las decisiones internacionales no han obligado a ningún país - si exceptuamos Alemania - a reducir efectivos (Carr e Ifantis, 1996), por lo que la merma en el tamaño de las fuerzas armadas responde más bien a procesos y causas internas de cada país, y 2) que las reducciones afectan básicamente al componente forzoso, es decir, hay menos jóvenes que realizan el servicio militar obligatorio y quienes cumplen con esta obligación lo hacen durante menos tiempo.

Esta reducción del componente forzoso y su eventual supresión definitiva se explica habitualmente en los medios institucionales como una consecuencia natural de la tecnologización - y nuclearización donde corresponda- de las fuerzas armadas. Por una parte, el armamento, cada vez más potente y demoledor, reemplaza a la fuerza humana. Por la otra, cada vez más sofisticado, ese 


\section{TABLA 4}

Proyección del tamaño de las fuerzas armadas europeas en el año 2002 y su relación con el tamaño poblacional

\begin{tabular}{ccccccccccc} 
Gre. & Nor. & Din. & Fra. & Por. & Bél. & Ale. & $R U$ & Hol. & Ita. & Esp. \\
\hline 140.000 & 29.000 & 24.000 & 250.000 & 38.000 & 40.000 & 320.000 & 225.000 & 60.000 & 190.000 & 123.000 \\
13,21 & 6,55 & 4,55 & 4,22 & 3,89 & 3,88 & 3,87 & 3,85 & 3,82 & 3,35 & 3,03 \\
& ++ & ++ & ++ & + & + & + & + & + & &
\end{tabular}

FUENTE para el tamaño poblacional: Wistat-CD, Nueva York: United Nations Population Fund. 
armamento exige personal militar más especializado, más motivado y más estable, más profesional (Burk, 1994). Que los dos ejércitos europeos mejor equipados, arsenales nucleares inclusive, hayan suprimido la conscripción es un dato que avala esta consideración; de hecho, las pruebas de Mururoa, cuya finalidad era actualizar el arsenal nuclear francés, han sido una condición previa para dar ese paso.

Esta lógica estratégica tiene, sin embargo, una contralógica democrática. La necesidad de personal más especializado descansa sobre la idea de que el período de formación del servicio militar obligatorio es demasiado corto. Sus doce meses apenas darían para una formación básica, inadecuada para los destinos más técnicos (Estrella, 1993). Pero ello no siempre ha sido así. En los años sesenta, la conscripción duraba una media de 18 meses en nuestro entorno europeo, y 24 meses en los años cincuenta. Es decir, la solución más sencilla y económica para asegurar una formación suficiente hubiera sido aumentar la duración de la prestación militar. Era la solución perfecta: además de disipar el fantasma de la caída demográfica, consolidaba el principio de la nación en armas. No ha podido ser, sin embargo, y ello porque la sociedad no lo habría consentido.

El fondo de esta cuestión es la aspiración social, casi siempre reprimida, a veces claramente visible, de suprimir la conscripción. Si revisamos los datos históricos, podría incluso decirse que la llamada profesionalización de las fuerzas armadas es, al menos en parte, la apropiación que la razón de Estado ha hecho de esa aspiración. Las autoridades empezaron a remunerar las estancias más largas asociadas a las funciones más técnicas como consecuencia de la reducción del servicio militar obligatorio, y no a la inversa. Tanto en los años veinte y treinta (Weber, 1964), como en los sesenta y setenta (Martin, 1977), como ahora en los noventa (Ajangiz, 2000), se repite inequívocamente la misma secuencia: primero se reduce la duración del servicio militar obligatorio y luego se formulan y acometen los planes de reorganización de las fuerzas armadas que refuerzan el componente de empleo. Pongamos el ejemplo de Francia: fue la reducción del servicio militar de 24 a 12 meses entre 1965 y 1969 la que desencadenó esa reestructuración militar que ahora culmina (Martin, 1977). O pongamos el ejemplo de España: la reducción a doce meses en 1986 y a nueve en 1991 dio paso a sendos programas de voluntariado remunerado, y lo mismo puede decirse de la decisión en 1996 de su abolición definitiva. Lo más llamativo es que esas reducciones y subsiguientes remodelaciones estructurales de las fuerzas armadas están asociadas a una movilización social. Es decir, es la protesta y resistencia civil contra el reclutamiento forzoso, enmarcada en un progresivo distanciamiento en relación con las fuerzas armadas de la sociedad en su conjunto, la que empuja a los gobiernos a profesionalizar la institución militar. Volveremos a esta idea un poco más adelante.

Así pues, la menor duración del servicio militar es una razón básica para explicar esa continuada pérdida en el volumen de efectivos que padecen las fuerzas armadas europeas desde hace al menos tres décadas. La otra razón bási- 


\section{FIGURA 1}

Duración del servicio militar obligatorio (en meses), 1980 a 1998

\begin{tabular}{|c|c|c|c|c|c|c|c|c|c|c|c|c|c|c|c|c|c|c|c|}
\hline & 1980 & 81 & 82 & 83 & 84 & 85 & 86 & 87 & 88 & 89 & 90 & 91 & 92 & 93 & 94 & 95 & 96 & 97 & 98 \\
\hline Alemania .................. & 15 & - & - & - & - & - & - & - & - & - & - & 12 & - & - & - & 10 & - & - & 一 \\
\hline Bélgica ................. & 10 & - & - & - & - & - & - & 12 & - & - & - & 11 & 10 & 8 & - & 0 & & & \\
\hline Dinamarca ...... & 9 & - & - & - & - & - & - & - & - & - & - & - & - & - & - & - & - & - & 一 \\
\hline España & 15 & - & - & - & - & - & 12 & - & - & - & - & 9 & - & - & - & - & - & - & - \\
\hline 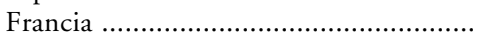 & 12 & - & - & - & - & - & - & - & - & - & - & - & 10 & - & - & - & - & - & - \\
\hline 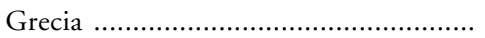 & 24 & 22 & - & - & - & - & 21 & - & - & 20 & - & 19 & - & - & - & - & - & - & - \\
\hline 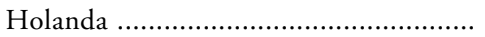 & 14 & - & - & - & - & - & - & - & - & - & - & 12 & - & - & 9 & - & 6 & 0 & \\
\hline 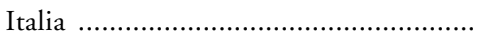 & 12 & - & - & - & - & - & - & - & - & - & - & - & - & - & - & - & - & 10 & - \\
\hline Noruega ............................................ & 12 & - & - & - & - & - & - & - & - & - & - & - & - & - & - & 9 & - & - & - \\
\hline 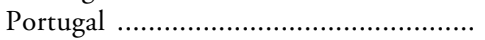 & 16 & - & - & - & - & - & - & - & - & - & 15 & - & 12 & - & 4 & - & - & - & - \\
\hline Turquía ............................................ & 20 & - & - & - & - & 18 & - & - & - & - & - & 15 & - & - & 18 & - & - & - & \\
\hline
\end{tabular}

FuENTES: Horeman et al. (1997), Kiljunen y Väänänen (1987), Quaker Council for European Affairs (1984), War Resisters International (1990) y noticias de prensa. 
ca es la disminución del aporte de conscriptos: son cada vez menos quienes cumplen con el servicio militar. Tres son las variables que determinan ese aporte: a) la evolución de la población reclutable, es decir, el factor demográfico; b) la resistencia al reclutamiento, normalmente la objeción de conciencia, y c) la presión de reclutamiento que decidan las autoridades en cada momento.

Para empezar, el impacto de la evolución demográfica es insignificante en la mayoría de los países porque el reclutamiento militar se sitúa normalmente alrededor del $50 \%$ de la población reclutable y las autoridades cuentan con margen de maniobra suficiente para regular la tasa de reclutamiento en función del volumen de efectivos que consideren necesario en cada momento. En realidad, tan sólo tres países, Alemania, Italia y España, han sufrido una merma del aporte de recluta forzosa en los últimos años. Es cierto que existe una importante caída demográfica, más acentuada en Italia y España que en Alemania, pero el verdadero causante de la reciente reducción de los efectivos militares en estos tres países es la objeción de conciencia. No existiría ninguna crisis de reclutamiento si, en vez de triplicarlos (ver figura 2), Alemania, Italia y España tuvieran los mismos niveles de objeción de conciencia que los demás países, siempre controlados por debajo del 10 ó 15\% del contingente. Veamos ahora las razones de esta singularidad.

\section{POSICIÓN DE LA SOCIEDAD SOBRE EL RECLUTAMIENTO FORZOSO Y RESISTENCIA CIVIL}

Las protestas contra el reclutamiento forzoso son una constante histórica (Forrest, 1989; Levi, 1997; Lucassen y Zürcher, 1998; Sales, 1974; Young, 1984). Digamos que la intensificación circunstancial del reclutamiento ha rebasado con frecuencia el umbral del consentimiento social. En este sentido, el cambio de valores y prioridades operado en la sociedad en las últimas décadas no habría hecho sino rebajar aún más ese umbral.

Como bien señala Shaw (1991), en las últimas décadas se ha producido un desplazamiento sociológico hacia la desmilitarización: a) de la vida cotidiana, y b) de la política nacional e internacional. Esta desmilitarización se manifiesta en términos de: 1) un progresivo distanciamiento - algunos autores lo han calificado de divorcio- entre fuerzas armadas y sociedad; 2) un rechazo cada vez más activo del servicio militar, y 3) una discrepancia básica entre las prioridades que establecen las autoridades en sus políticas militares, cuyo eje central son los intereses estratégicos nacionales, y las prioridades de sus sociedades, nucleadas en torno a los derechos humanos o la paz. Shaw habla de una sociedad postmilitar.

El hecho de que, ya en la década de los setenta, la política de defensa ocupase el último lugar en la escala de prioridades de todas las sociedades europeas occidentales (Inglehart, 1977: 49) sienta la base para poder afirmar que esa discrepancia y distanciamiento de la sociedad es más una realidad estructural 
que un episodio reciente. En función de un antagonismo básico entre warfare y welfare, Harries-Jenkins (1982) defendía hace algunos años que el desarrollo del Estado del bienestar había propiciado un cambio progresivo en los modos de legitimación de la institución militar. Que, en un primer momento, la legitimidad básica tradicional de las fuerzas armadas, en función de la cual se les asignaba un papel central en la construcción de la identidad nacional y en la defensa del interés del Estado, empezó a ser sustituida por una legitimidad funcional en la que las fuerzas armadas se entendían como una parte más del aparato administrativo del Estado. El siguiente paso, decía, sería su sustitución por una legitimidad democrática, por la que el Ejército sería aceptado en tanto en cuanto su existencia y la utilización que se hiciera de su poder fueran refrendadas por el conjunto de la sociedad. Las recientes intervenciones por razones humanitarias y de restablecimiento de la paz responden ya a esta legitimidad democrática.

La conscripción era el elemento más débil en ese contexto de cambio y foco de sus contradicciones más graves: era el emblema por excelencia de la legitimidad tradicional de lo militar y se exigía precisamente a los adelantados de los nuevos valores postmaterialistas (Inglehart, 1976). No es de extrañar, por tanto, que experimentara una primera crisis aguda a finales de los sesenta y primeros de los setenta. Cuatro son las circunstancias que definen esta crisis: 1) la objeción de conciencia dejó de ser una opción de minorías — siempre por debajo del 2\% del contingente- y comenzó a crecer significativamente, llegando a ser del 17\% en Dinamarca, 15\% en Alemania, 9\% en Noruega, 8\% en Holanda y 6\% en Bélgica (Mellors y McKean, 1982; Moskos y Chambers, 1993); 2) en algunos de los países que no reconocían todavía la objeción de conciencia, el caso de Francia, Italia o España, se organizó una desobediencia civil a tal efecto (Albesano, 1993; Ibarra, 1992; Martin, 1993); 3) soldados y conscriptos comenzaron a organizarse en sindicatos (Cortright y Watts, 1991), y 4) una movilización extensa en contra de la guerra de Vietnam obligó al gobierno de Estados Unidos a decretar la abolición de la conscripción (Chatfield, 1995; Useem, 1973).

Esta crisis tuvo un impacto apreciable en las políticas militares de Europa: una reducción generalizada de la duración del servicio militar obligatorio, a la mitad en muchos casos, y un replanteamiento de la estructura misma de las fuerzas armadas. Desde el punto de vista militar, aquella reducción supuso una devaluación de la conscripción; desde el punto de vista político, la comprensión de que tenía fecha de caducidad. Fue entonces cuando las autoridades decidieron potenciar el componente de empleo y profesionalizar de manera suficiente sus fuerzas armadas. Sin embargo, a diferencia de Estados Unidos, también apuntalaron el servicio militar obligatorio. Cierto que existían tradiciones distintas al respecto en los países anglosajones y la Europa continental, y también que los países europeos no estaban implicados en una guerra de intervención como la de Vietnam, pero una explicación cabal de esa diferencia debe hacer referencia a otras dos circunstancias al menos. 


\section{TABLA 5}

Objeción de conciencia en Europa

\begin{tabular}{|c|c|c|c|c|c|c|c|c|c|}
\hline & Ale. & Esp. & Ita. & Fra. & Nor. & Bél. & Hol. & Din. & Por. \\
\hline $1965 \quad$ ……........ & 3.437 & & & 67 & 400 & & & 490 & \\
\hline $1966 \ldots \ldots \ldots . . . . . .$. & 4.431 & & & 59 & & & & 540 & \\
\hline $1967 \ldots \ldots \ldots . . . .$. & 5.963 & & & 65 & & & & 672 & \\
\hline $1968 \ldots \ldots \ldots . . . .$. & 11.952 & & & 101 & & & 700 & 1.107 & \\
\hline 1969 ............... & 14.420 & & & 151 & & & & 1.766 & \\
\hline $1970 \ldots \ldots . . . .$. & 19.363 & & & 261 & & 89 & & 2.456 & \\
\hline $1971 \ldots \ldots \ldots . . .$. & 27.657 & & & 606 & & 112 & & 4.200 & \\
\hline $1972 \ldots \ldots \ldots . . .$. & 33.792 & & & 789 & & 272 & & 4.489 & \\
\hline $1973 \ldots \ldots \ldots . . . . . .$. & 35.192 & & 143 & 586 & & 792 & & 3.987 & \\
\hline $1974 \ldots \ldots \ldots . . . .$. & 34.150 & & 219 & 596 & 2.675 & 607 & 2.000 & 4.161 & \\
\hline $1975 \ldots \ldots \ldots . . . . . .$. & 32.565 & & 238 & 770 & & 766 & & 3.136 & \\
\hline $1976 \ldots \ldots \ldots . . . . . .$. & 40.618 & 597 & 628 & 766 & 2.090 & 913 & & 2.255 & 20 \\
\hline 1977 ................ & 34.692 & 650 & 790 & 878 & 2.120 & 897 & & 814 & 20 \\
\hline $1978 \ldots \ldots \ldots . . . . . . . . .$. & 39.698 & 700 & 1.103 & 1.200 & 2.020 & 1.190 & & 763 & 20 \\
\hline 1979 ............... & 45.454 & 726 & 1.769 & 1.208 & 2.224 & 1.448 & & 909 & 20 \\
\hline 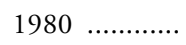 & 54.193 & 800 & 2.375 & 1.148 & 2.543 & 1.339 & 3.845 & 816 & \\
\hline 1981 .............. & 58.051 & 900 & 2.559 & 1.312 & 2.690 & 1.171 & 3.341 & 606 & \\
\hline $1982 \ldots \ldots \ldots . . . .$. & 59.776 & 1.000 & 6.917 & 1.147 & 2.812 & 2.011 & 2.936 & 466 & \\
\hline $1983 \ldots \ldots \ldots . . . . . . .$. & 68.334 & 1.106 & 7.557 & 2.250 & 2.372 & 2.023 & 2.705 & 366 & \\
\hline $1984 \ldots \ldots \ldots \ldots$ & 43.875 & 1.500 & 9.903 & 2.510 & 2.070 & 1.886 & 3.037 & 319 & \\
\hline 1985 .............. & 53.907 & 4.191 & 7.430 & 2.600 & 2.094 & 1.720 & 2.953 & 218 & \\
\hline $1986 \ldots \ldots \ldots . . . . . . .$. & 58.693 & 6.407 & 4.282 & 2.737 & 2.497 & 1.356 & 3.017 & 232 & \\
\hline $1987 \ldots \ldots \ldots \ldots$ & 62.817 & 8.897 & 4.986 & & 2.360 & 1.078 & 2.936 & 355 & \\
\hline $1988 \ldots \ldots \ldots \ldots$ & 77.048 & 11.049 & 5.697 & 2.950 & 2.281 & 949 & 2.768 & 484 & 704 \\
\hline $1989 \ldots \ldots \ldots . .$. & 77.432 & 13.130 & 13.746 & 2.861 & 2.286 & & 2.900 & 590 & \\
\hline $1990 \ldots \ldots \ldots \ldots$ & 74.309 & 27.398 & 16.767 & 3.172 & 2.539 & 1.600 & 3.000 & 500 & \\
\hline 1991 .............. & 151.214 & 28051 & 18.254 & & 2.666 & 6.000 & & 400 & \\
\hline $1992 \ldots \ldots \ldots . .$. & 133.868 & 42.454 & 23.490 & & 2.542 & & & & 501 \\
\hline $1993 \ldots . . . \ldots . . . . .$. & 131.057 & 68.209 & 28.910 & & 2.358 & 737 & & & 624 \\
\hline $1994 \ldots \ldots \ldots \ldots$ & 125.765 & 77.121 & 33.339 & 8.000 & 2.061 & & & & 425 \\
\hline $1995 \ldots . . . \ldots . . . .$. & 160.569 & 72.832 & 44.342 & 7.200 & 2.110 & & & & 382 \\
\hline 1996 ............... & 156.763 & 93.279 & 47.824 & & 2.302 & & & & 1.000 \\
\hline 1997 .............. & 154.972 & 127.304 & 54.867 & & 2.300 & & & & \\
\hline $1998 \ldots . . . \ldots \ldots . . .$. & 171.657 & 150.581 & 71.043 & & & & & & \\
\hline
\end{tabular}

Fuentes: Agirre et al. (1998), Albesano (1993), Auvray (1983), Horeman et al. (1997), Ibarra (1992), Kiljunen y Väänänen (1987), Moskos y Chambers (1993), Quaker Council for European Affairs (1984), War Resisters International (1990); páginas web de los departamentos gubernamentales competentes y de grupos pacifistas; noticias de prensa; comunicaciones personales de especialistas en la materia. Los datos en cursiva son aproximados. 
La primera, que en Europa no existió movilización organizada alguna que politizara esa suma de opciones individuales y planteara expresamente la supresión del servicio militar obligatorio. En opinión de Shaw (1991: 8), el gran potencial para la protesta antimilitarista que expresaron los movimientos pacifistas europeos en los primeros ochenta podría haber tenido profundas consecuencias si se hubiera organizado en contra de la conscripción. Los casos de Estados Unidos (Useem, 1973), Sudáfrica (Seegers, 1993) y España (Agirre et al., 1998) confirman esta suposición. Sin embargo, esta reivindicación ni tan siquiera entró en la agenda política europea de los años setenta y primeros ochenta. La razón principal, que su portavoz natural, el movimiento pacifista y antimilitarista, no era partidario de eliminar el servicio militar obligatorio. Hubo disidencia — por ejemplo, la FÖGA alemana impulsó una campaña de insumisión a principios de los ochenta y los españoles del MOC consiguieron que el ICOM, o red europea de organizaciones de objetores de conciencia, abrazara esa propuesta-, pero las estructuras centrales del movimiento creían en la doctrina del pueblo en armas y se resistieron a las tesis abolicionistas. En movimientos como el alemán, esta resistencia sigue existiendo aún hoy en día ${ }^{6}$.

Y la segunda, que los gobiernos implementaron medidas de contención suficiente para normalizar e integrar esa disidencia: trabas en el reconocimiento de la objeción de conciencia — preceptividad de informes positivos de terceros, coherencia de los antecedentes personales, razonamientos adecuados en la solicitud-, leyes restrictivas - no aceptación de algunos motivos o de la objeción sobrevenida-, denegación sistemática de un número importante de solicitudes - Alemania en los sesenta, Francia en los setenta, Noruega desde entonces hasta hoy-, duración disuasoria de la prestación sustitutoria - el doble que la militar en Francia, aumento progresivo en Alemania-, cárcel y represión para los desobedientes y, finalmente, un bloqueo absoluto de la agenda política a la cuestión del servicio militar obligatorio. En suma, una penalización suficiente de las alternativas y resistencia al reclutamiento forzoso.

Con todo, la década de los noventa ha supuesto una cierta reedición de aquel ciclo: la objeción de conciencia ha crecido significativamente y la agenda política ha incorporado el debate sobre la conveniencia de suprimir la conscripción. En torno a 1991, casi todos los países redujeron una vez más la duración del servicio militar. Aunque oficialmente se alude al fin de la guerra fría para justificar esta medida, lo cierto es que bien podría también interpretarse como esa decisión aplazada, largamente contenida, que exigía la impopularidad social de esta prestación. De hecho, esa reducción ha sido en muchos casos

${ }^{6}$ Relatos sobre el movimiento pacifista y su posición sobre la conscripción pueden encontrarse en Albesano (1993), Cattelain (1973), Della Porta y Rucht (1995), Duyvendak (1995), Gleditsch (1990), Ibarra (1992), Kiljunen y Väänänen (1987), Klandermans (1991), Koopmans (1995), Levi (1997), Lyons (1999), Massarrat y Betz (1998), Meulen y Manigart (1997), Moskos y Chambers (1993), Rochon (1988) y Sørensen (2000). 


\section{FIGURA 2}

\section{Indices de objeción de conciencia}

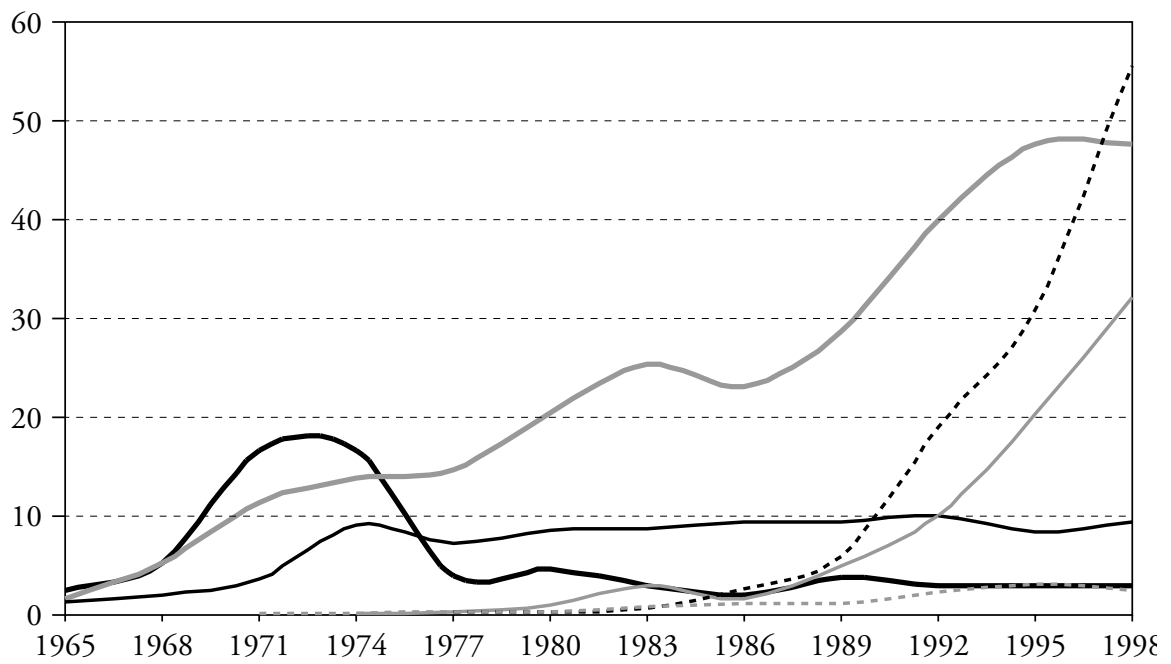

- Dinamarca - Alemania - Noruega - Italia -.. España =-= Francia

la antesala de su supresión definitiva. El contexto de esta decisión no podía ser más aleccionador: España, Italia y Alemania han conocido un extraordinario crecimiento de la objeción de conciencia y las conductas de evasión se han generalizado hasta en países como Francia y Bélgica, auténticos bastiones del servicio nacional y donde hasta entonces los índices de objeción de conciencia habían sido extremadamente bajos.

La extensión de la objeción de conciencia ha sido descrita por algunos autores como consecuencia del proceso de modernización que han vivido nuestras sociedades en los últimos cincuenta años: a mayor bienestar, menos afinidad con lo militar (Moskos y Chambers, 1993). Dos son los hechos que desafían esta interpretación en el contexto de las sociedades industriales avanzadas: a) siempre ha habido países con altos porcentajes de objeción de conciencia y otros donde esta conducta era prácticamente inexistente, y b) existe crecimiento negativo en algunos países. Por un lado, mientras en España, Italia o Alemania hay tantos objetores como reclutas forzosos - 56\% en España en 1998, 48\% en Alemania en 1998, y 49\% en Italia en 1999-, en Francia, Bélgica o Portugal los objetores nunca han llegado a superar el 5\% del contingente. Por otro, en Dinamarca o Noruega, por ejemplo, existen hoy 
menos objetores que hace treinta años. A la luz de estos hechos, en nuestra humilde opinión, sería más apropiado hablar de una creciente predisposición hacia la objeción de conciencia - o creciente aversión hacia el servicio militar- que requiere de ciertas condiciones propicias para expresarse conductualmente. Es decir, deberíamos distinguir entre potencia y acto: la potencia sería el cambio cultural, pero el acto estaría gobernado por factores de carácter básicamente político y coyuntural.

Nos explicamos. La verificación de un escenario de deslegitimación generalizada del servicio militar obligatorio es una condición necesaria pero no suficiente para que tenga lugar esa extensión de la objeción de conciencia. La conducta del conscripto se rige básicamente por un cálculo racional de coste y beneficio; preferiría no hacer la mili, pero no a cualquier precio. De ahí que las autoridades implementen medidas de penalización sobre la objeción de conciencia en grado suficiente para que ésta devenga en una conducta minoritaria. Siempre lo han hecho, lo que en cierta forma confirmaría la escasa legitimidad de esta prestación aun en tiempos anteriores a la expansión de esa sociedad postmilitar que describe Shaw. De hecho, también entonces existían resistentes. Su número era menor y, obviamente, tenían menos medios que los insumisos de hoy, pero sus formas de acción, discursos y demás coinciden asombrosamente: los relatos de los procesos de reconocimiento de la objeción de conciencia en Noruega, que tuvo lugar entre 1890 y 1922 (Agøy, 1990), y en España, entre 1971 y 1996 (Agirre et al., 1998), evidencian la misma desobediencia civil, el mismo ideario de antimilitarismo radical, los mismos modos de resistencia noviolenta, y hasta las mismas respuestas represivas del lado de las autoridades. Es decir, podría afirmarse que el conflicto entre actor movimiento y actor institucional en esta materia ha sido siempre básicamente el mismo y que su mayor impacto hoy en día radica en su mayor resonancia cultural, respaldo social y recursos organizativos del movimiento. Todo ello redundaría, en última instancia, en una reducción del agravio comparativo existente entre objeción de conciencia y servicio militar. En este sentido, ese crecimiento exponencial de la objeción de conciencia que han conocido España e Italia en los últimos años sería la mejor evidencia de que han fracasado las políticas de contención y penalización de la objeción de conciencia y ello ha reducido notablemente sus costes en relación con el servicio militar.

Esta banalización y coyunturalidad de la objeción de conciencia es de problemático encaje en la tradición del pensamiento liberal, que siempre la ha entendido como un acto individual enraizado en profundas convicciones, bien sean religiosas o seculares, un testimonio en sentido estricto. Por el contrario, es perfectamente inteligible si adoptamos una visión radical del juego político y las relaciones de poder: la colectivización de la objeción de conciencia nos remite a la existencia de un actor político que, más que una consideración especial para con su sensibilidad u opción particular, lo que exige es un cambio estructural de esa política militar. La abolición de la 
conscripción es una reivindicación clásica y central de la objeción de conciencia entendida como movimiento social. De hecho, en los inicios de la historia de la objeción de conciencia nos encontramos casi siempre con una desobediencia civil que quiere acabar con la prestación militar. Los relatos de Noruega, Dinamarca, Francia, Italia, España o la Turquía de hoy son buenos ejemplos. Esa movilización suele conseguir el reconocimiento formal de su oposición al servicio militar pero, paradójicamente, en razón de las medidas de control que se arrogan e implementan las autoridades, da también paso a una etapa de calma y asimilación del cambio en la que la desmovilización, descolectivización y despolitización más absoluta de la objeción de conciencia permiten, por lo general, un reforzamiento de los anclajes del servicio militar. En este contexto, repolitizar la objeción de conciencia a través del conflicto, por ejemplo una nueva desobediencia civil, es el medio más eficaz de que dispone el movimiento para neutralizar esas medidas de control y progresar hacia el fin de la conscripción. Así pues, el ciclo de vida de esta institución puede perfectamente explicarse a partir de esta dinámica de conflicto entre el actor institucional y el actor movimiento, eso que Tilly ha denominado contentious politics.

\section{FIGURA 3}

\section{Ciclo de vida de la conscripción desde el punto de vista de la interacción} entre el actor institucional y el actor movimiento

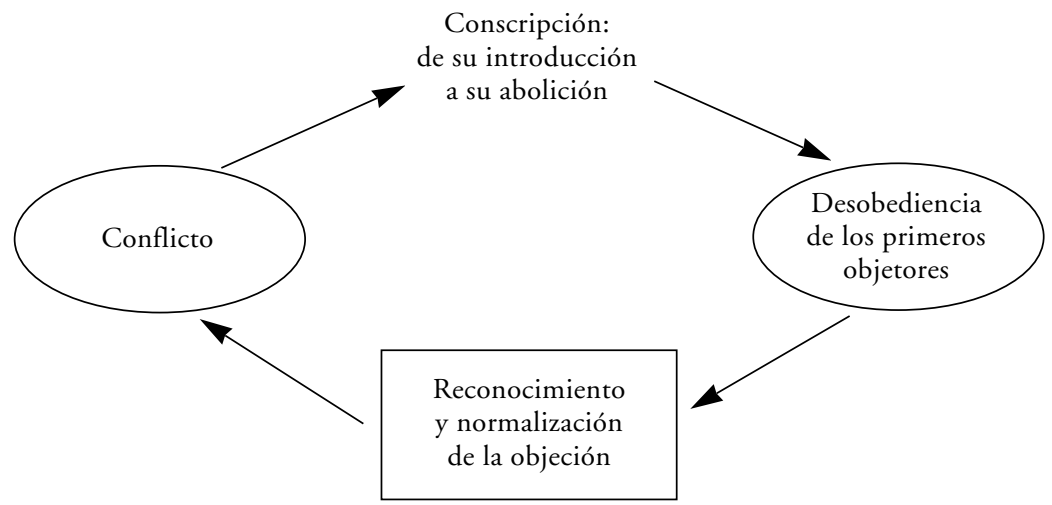

Estados Unidos y España son ejemplos cumplidos de esta dinámica de conflicto, Italia está en su última fase, y Alemania podría sumarse a esta relación si el movimiento pacifista se lo propusiera. La activación del conflicto, en forma de desobediencia, acontecimiento extraordinario o sucesión 
de reveses en la aplicación de la norma, ha promovido en todos estos casos una reducción suficiente del mayor coste de las alternativas al cumplimiento del servicio militar, animando su crecimiento hasta el punto de superar el umbral de seguridad de esa prestación militar y comprometer su abolición.

En Alemania, las movilizaciones en contra de la incorporación de su país a las intervenciones militares de la OTAN se sumaron a las consecuencias del vacío de poder que en materia de conscripción supuso la caída del régimen de la ex Alemania del Este y, también, al sentimiento de que la reunificación revocaba amenazas previas para impulsar un notable crecimiento de la objeción de conciencia. No ha llegado a superar el umbral de seguridad del servicio militar, pero se halla muy cerca de hacerlo. Las autoridades cuentan con un cierto margen de maniobra - de hecho, reclutan a todos los objetores disponibles pero no a todos los reclutas disponibles-, pero el repunte demográfico que ha salvado la situación remitirá en un plazo de diez años y cualquier incremento extraordinario de la objeción de conciencia significaría una merma directa del número de incorporados al servicio militar obligatorio.

En Italia, la estrategia de reforma consistente en un recurso sistemático a los tribunales de justicia que el movimiento abrazó en los años ochenta -Farné y Protti (1996) lo han definido como una "colaboración obediente»ha logrado, finalmente, una significativa reducción de los costes personales de la prestación sustitutoria en relación con el servicio militar: desde 1998 ambas prestaciones duran lo mismo y, aunque la prestación sustitutoria se cumple a rajatabla, al menos se cumple cerca de casa y en un entorno no amenazante ${ }^{7}$. A ello debe añadirse la campaña a favor de la abolición de la conscripción que inició, también en 1998, el Partido Radical.

Pero es España el caso más flagrante de inversión de costes. La desobediencia civil que promovió el movimiento antimilitarista a partir de 1988, y que consiguió reunir a unos 20.000 insumisos en el espacio de ocho años, no tiene precedentes en Europa en cuanto a su volumen e impacto. Este movimiento no sólo se erigió en portavoz de esa aspiración mayoritaria latente en la sociedad española de acabar con la conscripción, sino que, además, creó las condiciones necesarias para que se diese ese paso. La insumisión fue el factor básico que animó ese crecimiento exponencial de la objeción de conciencia, que a su vez se convirtió en causa de fuerza mayor para que el actor institucional decidiera suprimir definitivamente la conscripción en 1996, por la sencilla razón de que le resultaba imposible asegurar un número suficiente de reclutas incluso a corto plazo. El acuerdo político entre populares y nacionalistas catalanes fue, en este contexto, de lo más oportuno.

Las prácticas de nonnismo o abusos en los cuarteles son una constante en las fuerzas armadas de este país. 


\section{FIGURA 4}

Proceso de la abolición de la conscripción en España

\begin{tabular}{|c|c|c|}
\hline Politica formal & Sociedad & Movilización \\
\hline Consenso & Rechazo pasivo & - Insumisión \\
\hline $\begin{array}{c}\text { Cambio de posición } \\
\text { de partidos periféricos } \\
\text { y división dentro } \\
\text { de los mayoritarios }\end{array}$ & Rechazo activo & $\begin{array}{c}\text { Inhabilitación y } \\
\text { deslegitimación } \\
\text { de la prestación } \\
\text { sustitutoria }\end{array}$ \\
\hline & $\begin{array}{l}\text { Crecimiento } \\
\text { de la objeción } \\
\text { de conciencia }\end{array}$ & \\
\hline $\begin{array}{l}\text { Final de la } \\
\text { conscripción }\end{array}$ & $\begin{array}{l}\text { No hay } \\
\text { reclutas }\end{array}$ & \\
\hline
\end{tabular}

En la figura 4 se ilustra el vínculo entre la movilización y el final de la conscripción. El movimiento del cambio va de izquierda a derecha. En primer lugar, la popularización de la objeción de conciencia como la mejor vía de escape a la obligación militar debe mucho a la insumisión. Por un lado, la movilización se adelantó a la puesta en marcha de la prestación sustitutoria, condicionando su legitimidad y desarrollo posterior. Sin medios o estructura administrativa suficiente y sin la colaboración inicial de unas entidades sociales que interpretaron esta prestación como un instrumento para legitimar la represión de los desobedientes, la Administración se enfrentó a un déficit estructural creciente de puestos de destino que ninguno de los planes especiales a tal efecto pudo nunca resolver. En la práctica, ello se tradujo en una retahíla de exenciones de la prestación o rebajas sustantivas en su cumplimiento que redujo abruptamente sus costes en relación con el servicio militar. Por otro lado, la notoria incapacidad de las autoridades para reprimir efectivamente la desobediencia radical inhabilitó, consecuentemente, su capacidad formal de exigir el cumplimiento de la prestación sustitutoria.

Convertida en la opción más apetecible, la objeción de conciencia creció en progresión geométrica, agravando así el déficit de puestos de prestación sustitutoria. Como se puede observar en la figura 5, la previsión era más que sombría cuando el gobierno decidió abolir la conscripción a comienzos de 1996. 


\section{FIGURA 5}

Gestión del sistema de prestación sustitutoria en España:

objetores incorporados y pendientes de incorporación en las fechas anteriores a la decisión de abolir la conscripción

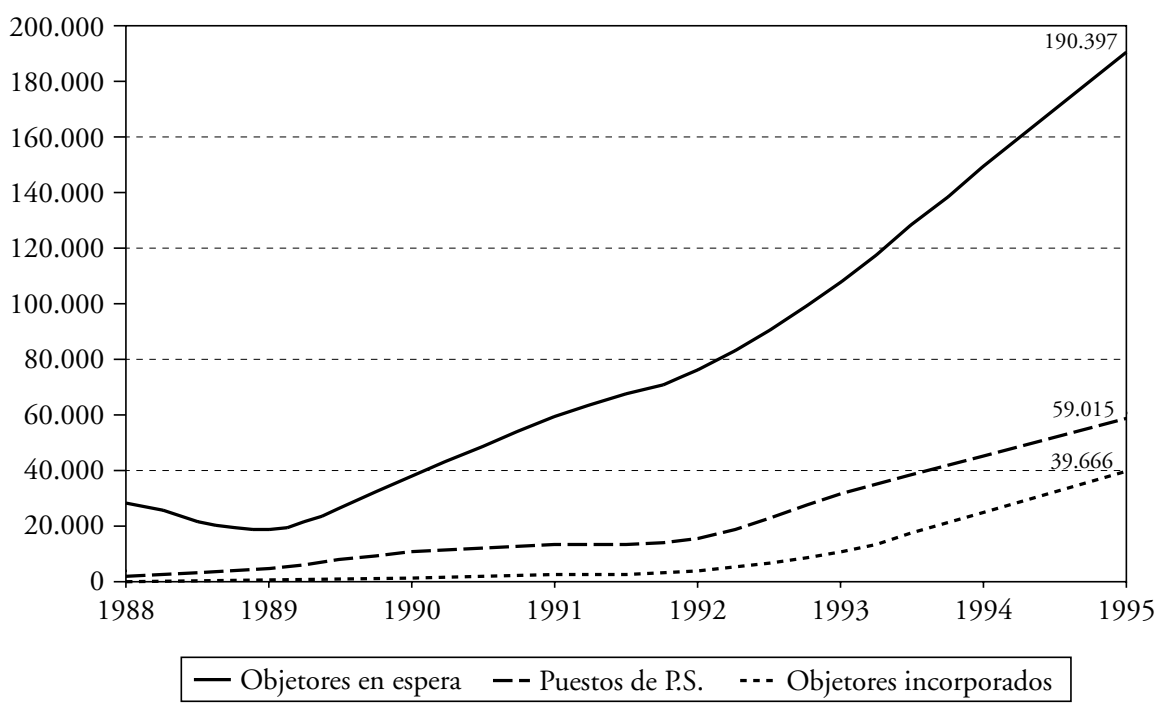

Fuente: Oficina para la Prestación Social de los Objetores de Conciencia, Ministerio de Justicia. La diferencia existente entre el número de puestos de prestación sustitutoria y el número de objetores incorporados se explica en parte por los 13 meses que duraba esta prestación.

La normalización de la prestación sustitutoria llegó demasiado tarde, cuando estaba a punto de ser suprimida. Con todo, no deja de ser paradójico que esta normalización se lograra a costa de rebajar sus costes formales —igualar su duración con el servicio militar y convalidar rutinariamente los llamados servicios previos-, es decir, haciéndola aún más apetecible, si cabe, que la prestación militar.

En segundo lugar, la insumisión fue la que introdujo la demanda de supresión del servicio militar obligatorio en la agenda política; hasta entonces, los ejes del debate eran la duración del servicio militar y las condiciones de la prestación sustitutoria. Y lo hizo de manera diáfana: negándose a la exigencia conscriptiva en sus dos modalidades. Además, el actor movimiento abrió fisuras al consenso político impulsando gestos e iniciativas que movilizaron a los partidos políticos periféricos; por ejemplo, el Manifiesto por la Abolición del Servicio Militar. 
En cualquier caso, esta movilización no hubiera tenido las consecuencias que observamos hoy de no haber contado con la complicidad de una opinión pública favorable a la desaparición del servicio militar obligatorio. Más arriba hemos constatado que en las últimas décadas las sociedades europeas han ido distanciándose progresivamente de lo militar, y que la crisis del servicio en armas no es sino una de las primeras manifestaciones de ese divorcio entre fuerzas armadas y sociedad. Sin embargo, paradójicamente, los datos de opinión pública al respecto en los años setenta y ochenta daban a entender que la conscripción disfrutaba de buena legitimación social. Esta aparente contradicción podría explicarse desde la cultura política: la sociedad entendía la conscripción como una salvaguarda frente a una institución militar que axiológicamente era cada día más ajena. Pero también podría argumentarse que nunca existió esa crisis social de la conscripción que estamos dando por buena, o que sólo afectaba, incluso coyunturalmente, a las generaciones más jóvenes.

La sorpresa llega en los años noventa. Las encuestas reflejan un abrupto cambio de opinión a veces en cuestión de meses: el apoyo a la conscripción se convierte en rechazo. Tanto o más sugerente resulta que el estímulo del cambio no sea un intenso debate nacional que ayude a replantear esa arraigada convicción, sino el simple conocimiento de que un país vecino ha decidido suprimir la conscripción o las declaraciones de un destacado líder político desmarcándose de la defensa institucional de la conscripción que, sin fisuras, ha dominado los últimos treinta años. Francia es un buen ejemplo: la oposición a la conscripción, que era del 41\% en 1994 (Le Figaro, 3-2-95), subió hasta un 72\% cuando Chirac dio a conocer sus planes para suprimirla (Le Monde, 23-2-96). España, el único país europeo donde ya en los años ochenta existía una opinión contraria al servicio militar obligatorio, es también el único país europeo donde el movimiento pacifista y antimilitarista planteaba su abolición y prometía una desobediencia civil a tal efecto; de hecho, las primeras encuestas al respecto se hicieron para comprobar si esa reivindicación tenía una efectiva base social (Ajangiz, 1992).

TABLA 6

Cambio en la posición de la opinión pública sobre la conscripción (en porcentajes)

\begin{tabular}{|c|c|c|c|c|c|}
\hline & España & Francia & Holanda & Italia & Bélgica \\
\hline Rechazo de la conscripción en los ochenta .................... & 63 & 24 & No & 34 & No \\
\hline 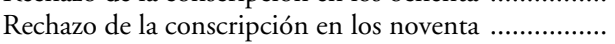 & 75 & 72 & 70 & 53 & Sí \\
\hline
\end{tabular}

FUENTES: ECO, octubre 1985, y CIS, núm. 2234, septiembre 1997, para España; SOFRES, septiembre 1986, y Le Monde, 22 febrero 1996, para Francia; Meulen y Manigart (1997: 322), para Holanda; Battistelli (1997), para Italia; y Thuysbaert (1994), para Bélgica. 
Este súbito y francamente radical cambio de opinión nos lleva a pensar que, durante muchos años, la opinión pública ha estado expresando una posición más pragmática que ideológica, que su apoyo a la conscripción derivaba de la convicción de que el servicio militar era tan inevitable como incuestionable. Desde luego, el ámbito político ofrecía un consenso sin fisuras: militares, gobernantes, parlamentarios, líderes políticos y hasta el mismo movimiento pacifista defendían la vigencia de la conscripción. Ahora sabemos que este discurso público era perfectamente compatible con un debate interno y exquisitamente restringido sobre las condiciones de supresión del servicio militar obligatorio, estudios de viabilidad incluidos. Francia es un buen ejemplo (Chicken, 1996). En este contexto, los discursos legitimatorios del servicio militar obligatorio, aun suponiendo a sus comunicadores la convicción necesaria, habrían jugado una función elemental de contención social y política de cualquier cambio en relación con una política militar que la sociedad europea no compartía con la necesaria convicción. El hecho de que esos comunicadores hayan sido, casi siempre, representantes de partidos con responsabilidades de gobierno - presentes o futuras - refuerza esta suposición.

En realidad, es muy posible que la conscripción, más que un fin en sí misma, haya sido siempre, básicamente, un medio para dotar a las fuerzas armadas del volumen de tropa marcado por las exigencias del momento. En tal supuesto, asegurar su cumplimiento habría sido el objetivo esencial de todo gobierno, y ello con independencia de lo que la sociedad pudiera pensar a tal efecto, del grado de legitimidad social de esa prestación militar. Es decir, la razón de Estado quedaría por encima de la razón democrática. De hecho, en la práctica, la política de la conscripción, junto a todas las demás políticas públicas en el ámbito de la defensa y seguridad nacional, integra un dominio de perfil alto (high-profile policy domain; Burstein, 1991). Este tipo de políticas públicas son habitualmente decididas por un número muy limitado de actores, básicamente las autoridades civiles y militares y los partidos mayoritarios o habituales del gobierno, y su criterio rector no es otro que los llamados intereses de Estado (Hilsman et al., 1993). Este formato de decisión, inmune en buena medida a las convocatorias electorales, deviene en un estilo de gobierno impositivo (top-down) que dificulta notablemente la intervención de otros actores políticos, así como un control efectivo desde la sociedad civil ${ }^{8}$. Posiblemente, la única forma de influir en una política de ese tipo sería promover una movilización con un perfil excepcionalmente alto; quizá por esta razón es tan habitual el recurso a la desobediencia civil por parte del movimiento pacifista

${ }^{8}$ Ejemplo de este estilo impositivo y de la prevalencia de la razón de Estado sobre la razón democrática, además de las políticas ya comentadas del gasto militar o de la misma conscripción, sería la disarmonía entre el enorme desarrollo armamentista que se produjo en la última década de la guerra fría y la convicción social de que, al contrario de lo que argumentaban los gobiernos de Europa occidental, no existían amenazas creíbles a la integridad territorial de esos países. Más aún, algunas opiniones públicas europeas consideraban la política militar agresiva de su aliado Estados Unidos como la mayor amenaza para la paz (Ramos, 1987; Smet, 1990). 
(Della Porta y Diani, 1997; Giugni et al., 1999; Kriesi et al., 1995; Pagnucco y Smith, 1993).

\section{CONSCRIPCIÓN Y DESARROLLO DE LAS FUERZAS DE ACCIÓN RÁPIDA}

La oposición de la sociedad civil al envío de conscriptos a las misiones de intervención exterior explica en buena medida la creación de fuerzas de acción rápida integradas exclusivamente por soldados de empleo. Todos los países cuentan en su haber histórico con experiencias de resistencia social al respecto. Pero fue después de la II Guerra Mundial cuando el descontento social en general, y más específicamente las protestas de los afectados, empujaron a los gobiernos a encontrar alternativas. La guerra de Corea y la campaña del Canal de Suez en el caso del Reino Unido (Dietz y Stone, 1975; Downes, 1991), la guerra de Argelia en el caso de Francia (Martin, 1977), y las guerras de Corea y Vietnam en el caso de Estados Unidos (Cohen, 1985; Janowitz, 1975), determinaron la decisión gubernamental de prescindir de los reclutas forzosos en este tipo de misiones y poner a soldados de empleo en su lugar. Ya en los noventa, la guerra del Golfo tuvo el mismo efecto en países como España, Italia o Alemania y, en general, estimuló la progresión hacia el modelo de empleo. Esta progresión, en un contexto estratégico dominado por las misiones de intervención militar exterior, ha decidido a algunos gobiernos europeos a suprimir directamente la conscripción (Dandeker, 1994b; Huesca González, 1994; McKenna, 1997), exactamente el mismo proceso que vivió Estados Unidos en los años setenta. En resumidas cuentas, podríamos decir que existe una secuencia segura, histórica, que relaciona las misiones de intervención exterior y el proceso de declive de la conscripción en los siguientes términos: intervención exterior $\rightarrow$ oposición social $\rightarrow$ supresión de la conscripción (Agirre et al., 1998).

El desarrollo suficiente de las fuerzas de acción rápida suele preceder a la supresión de la conscripción, sobre todo cuando se quiere asegurar una transición estructural ordenada de unas fuerzas armadas pensadas para la defensa territorial a unas fuerzas de defensa regional o intervención exterior; una secuencia inversa delataría un control deficiente de las políticas militares en general y de la política del servicio militar en particular. Como se puede observar en la tabla 7, a mediados de los noventa, es decir, antes de decidir la supresión de la conscripción, Francia, Alemania, Bélgica, Holanda, obviamente el Reino Unido, pero también Italia: a) habían programado que aproximadamente una cuarta parte del volumen total de sus fuerzas armadas integrase esas fuerzas de acción rápida; $b$ ) estaban asignando a las misiones de intervención exterior entre el 4 y el $6 \%$ de su volumen total de efectivos, y $c$ ) además, si exceptuamos Alemania, contaban con una tradición previa en ese tipo de misiones. Dinamarca y Noruega, a pesar de que sus soldados se mostraban 
reticentes a participar en esas misiones, cumplían sus compromisos con cierta holgura; tan sólo España y Portugal se hallaban aún lejos del objetivo: no existía una programación explícita al respecto ni tampoco contaban con un volumen suficiente de efectivos en esas fuerzas.

\section{TABLA 7}

Previsión de fuerzas de acción rápida y despliegue máximo habido en Bosnia (SFOR) o Kosovo (KFOR)

\begin{tabular}{|c|c|c|c|c|c|c|c|c|c|c|}
\hline & $R U$ & Fra. & Ale. & Hol. & Bél. & Ita. & Din. & Nor. & Esp. & Por. \\
\hline Experiencia previa ............ & Sí & Sí & No & Sí & Sí & Sí & No & No & No & No \\
\hline Año de introducción ...... & - & 1993 & 1993 & 1993 & 1993 & 1993 & 1994 & 1996 & 1995 & 1994 \\
\hline Número previsto efectivos.. & 60.000 & 60.000 & 54.000 & 15.000 & 10.000 & 30.000 & - & - & - & - \\
\hline $\begin{array}{l}\text { Porcentaje del volumen to- } \\
\text { tal }\end{array}$ & 27 & 24 & 28 & 25 & 24 & 16 & & & & \\
\hline SFOR/KFOR .................... & 13.000 & 10.500 & 8.300 & 2.300 & 1.700 & 5.900 & 850 & 900 & 1.700 & 240 \\
\hline $\begin{array}{l}\text { Porcentaje del total de em- } \\
\text { pleo }\end{array}$ & 6,0 & 4,6 & 4,4 & 4,0 & 4,0 & 4,2 & 3,4 & 3,1 & 1,8 & 0,8 \\
\hline Valor en la matriz final ... & ++ & ++ & ++ & ++ & ++ & ++ & + & + & & \\
\hline
\end{tabular}

FUENTE para el despliegue: Página web de la OTAN.

\section{CONSOLIDACIÓN DEL MODELO DE EMPLEO}

Más arriba hemos hecho mención de la modernización tecnológica como una condición necesaria para suprimir la conscripción, y ahora mismo acabamos de establecer el desarrollo suficiente de las fuerzas de acción rápida como otro de los requisitos. Pero, sin lugar a dudas, el parámetro más relevante a tal efecto es la progresión en el modelo de empleo: contar con un número suficiente de soldados de empleo antes de prescindir de los reclutas forzosos es sencillamente básico.

La consolidación del modelo de empleo es un proceso a largo plazo. De hecho, los países que hoy en día se ajustan en mayor medida a este modelo son aquellos que, espoleados por las movilizaciones de resistencia al reclutamiento, comenzaron a potenciar decididamente el voluntariado remunerado hace ahora treinta o cuarenta años. En los años ochenta, el personal de empleo, soldados incluidos, superaba el $50 \%$ del total de los efectivos en las fuerzas armadas de Dinamarca, Bélgica, Alemania, Holanda; en España este porcentaje se situaba en torno al $25 \%$, precisamente porque no contaba con soldados de empleo. 


\section{TABLA 8}

Evolución de la proporción del personal de empleo desde 1970 (en porcentajes)

\begin{tabular}{|c|c|c|c|c|}
\hline & 1970 & 1980 & 1989 & 1999 \\
\hline Reino Unido …................................ & 100 & 100 & 100 & 100 \\
\hline 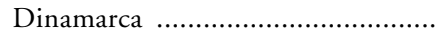 & 55 & 70 & 71 & 77 \\
\hline Bélgica & & 66 & 64 & 100 \\
\hline 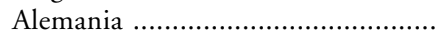 & 48 & 55 & 58 & 57 \\
\hline 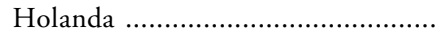 & 42 & 52 & 57 & 100 \\
\hline 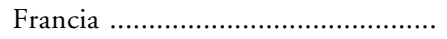 & 47 & 47 & 48 & 67 \\
\hline 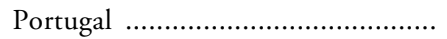 & & 47 & 44 & 87 \\
\hline 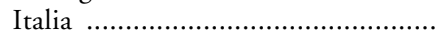 & 26 & 35 & 32 & 52 \\
\hline Noruega & 27 & 27 & 36 & 38 \\
\hline 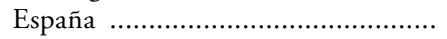 & 18 & 24 & 26 & 45 \\
\hline
\end{tabular}

Esta progresión ha sido acelerada en los noventa. La reducción generalizada del servicio militar, de una parte, y el veto social al envío de conscriptos a las intervenciones militares en el extranjero, de otra, han hecho aún más imprescindible el reclutamiento voluntario (Buffotot, 1997b). La reducción general del número de efectivos que comporta la sustitución de soldados forzosos por soldados de empleo ha obligado también a un importante reajuste del número de oficiales. En la actualidad, gracias en buena medida a los grandes progresos en la consolidación del modelo de empleo que se hicieron en las dos décadas anteriores, casi todos los países mencionados han completado esas reformas o están muy cerca de hacerlo. A 31 de diciembre de 1998, el Reino Unido, Holanda, Bélgica y Francia superaban el 90\% de los efectivos de empleo previstos en sus modelos de fuerzas armadas para este siglo entrante; sólo Italia y España estaban aún bastante lejos de su objetivo.

\section{TABLA 9}

Grado de cumplimiento de los programas de reestructuración del componente de empleo en las fuerzas armadas

\begin{tabular}{|c|c|c|c|c|c|c|}
\hline & $R U$ & Hol. & Bél. & Fra. & Ita. & Esp. \\
\hline \multicolumn{7}{|l|}{ Componente de empleo en } \\
\hline 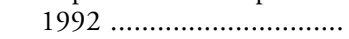 & 293.000 & 47.000 & 49.000 & 219.000 & 130.000 & 78.000 \\
\hline \multicolumn{7}{|c|}{ Componente de empleo en } \\
\hline 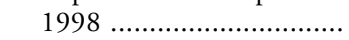 & 217.000 & 57.000 & 43.000 & 229.000 & 140.000 & 96.000 \\
\hline Número previsto de efectivos .. & 225.000 & 60.000 & 40.000 & 251.000 & 200.000 & 150.000 \\
\hline 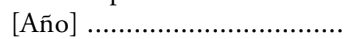 & [2002] & {$[2000]$} & [1996] & {$[2002]$} & [2008] & [2002] \\
\hline Grado de cumplimiento (\%).. & 96 & 95 & 93 & 91 & 70 & 64 \\
\hline
\end{tabular}


Para mejor valorar este extremo es preciso establecer comparaciones entre los países estudiados. A fin de cuentas, la mayoría de los gobiernos europeos manifiesta una evidente voluntad de homogeneización al respecto. El criterio de un modelo europeo de empleo bien podría ser la cifra de 3,9 militares por cada 1.000 habitantes, la media aritmética de los objetivos del Reino Unido, Bélgica, Holanda, Francia y España. Pues bien, en función de este criterio, hace aproximadamente diez años que Bélgica, Francia y Dinamarca se encontraban ya en condiciones de prescindir del reclutamiento forzoso; Holanda, Alemania, Portugal y Noruega podían sumarse a esa decisión sin demasiadas complicaciones, y sólo España e Italia seguían necesitando del servicio militar obligatorio para disponer de efectivos suficientes en relación con su tamaño poblacional.

\section{TABLA 10}

Nivel de cumplimiento de un modelo de fuerzas armadas sin recluta forzosa (3,9 militares de empleo por cada 1.000 habitantes) a principios y a finales de los noventa

\begin{tabular}{rccccccccccc}
\hline & Bél. & Fra. & Hol. & RU & Din. & Por. & Nor. & Esp. & Ita. & Ale. \\
\cline { 2 - 10 } & & & & & & & & & & \\
Componente de empleo & & & & & & & & & & \\
$\quad$ en 1992 ................... & 4,88 & 3,82 & 3,10 & 5,05 & 3,48 & 2,84 & 2,80 & 2,00 & 2,29 & 3,04 \\
Nivel cumplimiento (\%) ... & 125 & 98 & 80 & 130 & 89 & 73 & 72 & 51 & 59 & 78 \\
Componente de empleo & & & & & & & & & \\
$\quad$ en 1998 .................... & 4,21 & 3,89 & 3,65 & 3,62 & 3,19 & 3,12 & 2,71 & 2,44 & 2,43 & 2,31 \\
Nivel cumplimiento (\%) ... & 108 & 100 & 94 & 93 & 82 & 80 & 70 & 63 & 62 & 59 \\
Valor en matriz final ...... & ++ & ++ & ++ & ++ & + & + & & & & \\
\hline
\end{tabular}

De entre todos esos países, Bélgica, Holanda, Francia, España e Italia son los que efectivamente han dado ese paso. En el momento de la decisión gubernamental, las fuerzas armadas belgas se encontraban prácticamente al cien por cien en personal de empleo, si bien tenían que prescindir de algunos oficiales y reclutar a soldados de empleo en su lugar; a las holandesas les faltaban 15.000 soldados, 50.000 a las francesas, 78.000 a las italianas y 90.000 a las españolas. Es decir, esa decisión implicaba un menor esfuerzo en los dos primeros casos y más exigente en los otros tres. Con todo, los datos demuestran que Francia ha sabido dosificar ese esfuerzo: al día de hoy, prácticamente ha cumplido su objetivo. Por el contrario, los italianos no terminan de despegar — su Senado ha tardado un año en ratificar la abolición del servicio militar obligatorio-, y los españoles llevan un acusado retraso de plazos en un contexto de agotamiento - menos solicitudes que plazas convocadas - del potencial de reclutamiento. Para acercar el objetivo, el gobierno español decidió reducir la cifra final de 
120.000 a 110.500 soldados de empleo a comienzos del pasado año 2000. Un objetivo todavía lejano si se tiene en cuenta que los efectivamente reclutados en marzo del 2002 han sido 73.449. De hecho, Defensa se está planteando establecer en 75.000 el objetivo máximo de reclutamiento.

Estos datos confirman que suprimir el servicio militar obligatorio en Italia y España ha sido, al menos desde el punto de vista de la evolución estructural de las fuerzas armadas, una opción precipitada. De hecho, muy poco antes de adoptar esta delicada decisión, los líderes de ambos países descartaban la supresión de la conscripción y apostaban por un modelo mixto de ejército como opción más realista ${ }^{9}$. Lo razonable hubiera sido evolucionar sustancialmente hacia el modelo de empleo antes de suprimir la conscripción, sobre todo teniendo en cuenta las enormes dificultades que tiene el reclutamiento hoy en día. Las experiencias de los otros países advertían que las condiciones de reclutamiento de soldados de empleo en Italia y España eran muy desfavorables: descenso del desempleo, paga deficiente, orientación predominantemente institucional de las fuerzas armadas, endogamia y una sociedad distanciada de lo militar. En tales circunstancias, la supresión del reclutamiento forzoso no hacía sino empeorar las cosas. A la vista están sus consecuencias: para evitar un quebranto mayor, los responsables militares españoles han tenido que abaratar las exigencias de ingreso e incorporar a numerosas mujeres ${ }^{10}$. Pero quienes les sucedieron en las tareas de gobierno se encontraron con una situación insostenible: las fuerzas armadas de ambos países se estaban quedando sin reclutas forzosos. Así las cosas, aunque impuesta por los acontecimientos y extraordinariamente problemática, debemos reconocer que la decisión ha sido oportuna.

\section{RECAPITULANDO INDICADORES}

Las diez variables analizadas permiten construir un modelo explicativo de las decisiones gubernamentales adoptadas en los últimos tiempos en relación con la política de la conscripción. La primera conclusión que arroja este estudio es que resulta imprescindible entender esa decisión como el punto de llegada de un proceso que se inició hace cuatro décadas. En tal proceso hemos observado que, si bien factores como la nuclearización o la modernización tecnológica de las fuerzas armadas han jugado su papel, ha sido la razón democrática, entendida ésta como la alianza entre el deseo de la sociedad de prescindir de la conscripción y las movilizaciones de resistencia habidas en ese tiempo, la que ha ido progresivamente acotando la utilidad estratégica de la conscripción

9 Valgan como ejemplos las declaraciones del presidente italiano, Romano Prodi (Le Monde, 25-1-97), y del ministro español de Defensa, Julián García Vargas (El País, 29-5-94). Por modelo mixto entendían una tasa de empleo del $50 \%$.

${ }^{10}$ La situación actual podría ser más desesperada que lo que oficialmente se reconoce. El reciente intento de reclutar hijos de emigrantes o la propuesta de aceptar inmigrantes son gestos improbables cuando las perspectivas son tranquilizadoras. 
hasta el punto de convertirla, al menos desde un punto de vista militar o estratégico, en una institución perfectamente prescindible. La progresiva reducción de su duración y el veto al empleo de conscriptos en las misiones internacionales han sido los dos ejes principales de esa depreciación.

\section{FIGURA 6}

\section{Factores relevantes en la abolición de la conscripción}

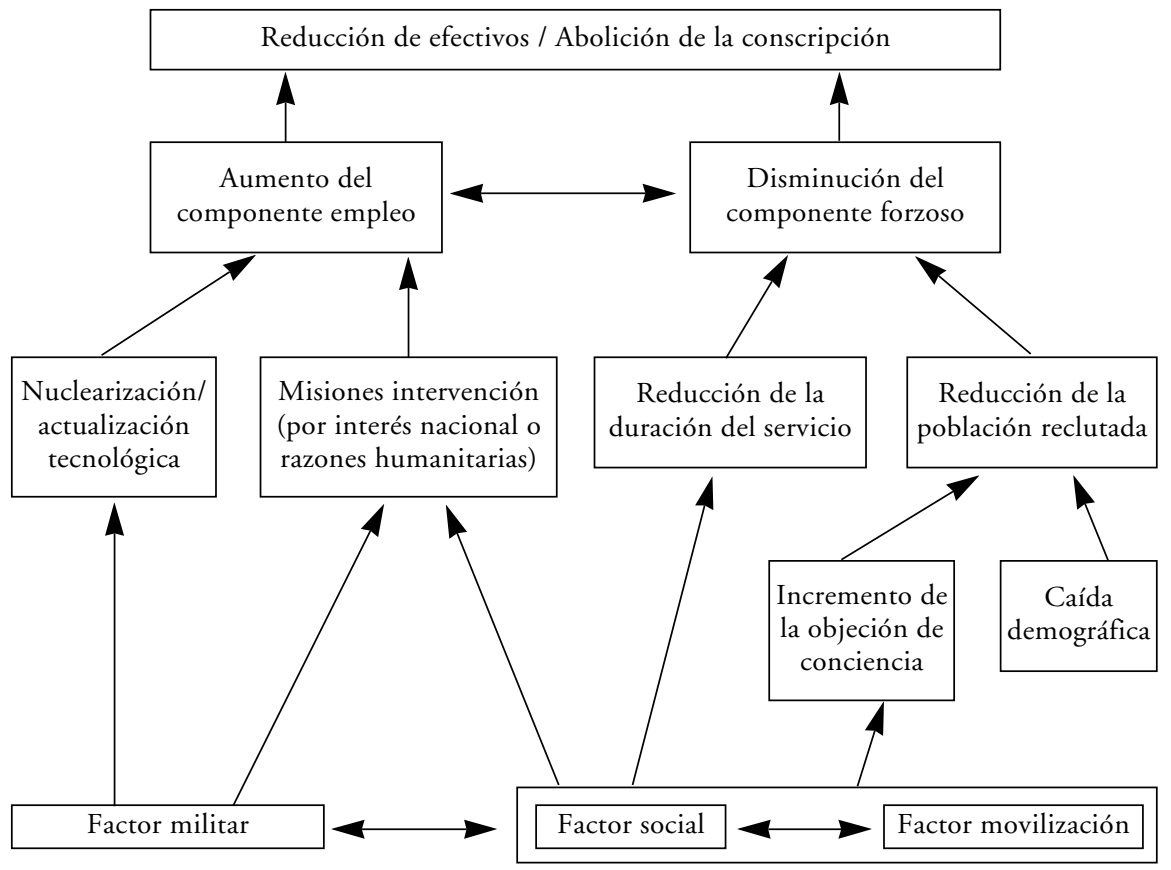

Si hubiera prevalecido la razón de Estado o si la conscripción hubiera realmente disfrutado de la legitimidad social que le suponía el actor institucional, no existiría problema alguno para implementar un reclutamiento obligatorio de hasta dos años de duración — suficiente para una formación adecuadacomo el que existía en los primeros años sesenta, y serían reclutas forzosos y no soldados de empleo los que hoy participarían en las misiones internacionales; desde el punto de vista del coste y de la integración entre fuerzas armadas y sociedad, ésta habría sido, sin lugar a dudas, la opción óptima. La evolución actual hacia el modelo de empleo debe entenderse, pues, como un triunfo de esa razón democrática que quería desembarazarse de obligaciones militares directas. 
La reforma final que ha consolidado ese modelo de empleo ha llegado en los años noventa. Éste ha sido el momento elegido por las autoridades de Bélgica, Holanda, Francia, España e Italia para decidir el fin del servicio militar obligatorio; Portugal está en camino. La decisión no ha sido, sin embargo, unánime: esta prestación militar sigue existiendo en Dinamarca, Noruega y Alemania. Esta diversidad no contradice la realidad constatada de que todas las fuerzas armadas tienden al modelo de empleo, confirma tan sólo que el fin del servicio militar obligatorio no es una consecuencia obligada de la consolidación de este modelo. Unas fuerzas armadas fundamentadas en el modelo de empleo no tienen por qué renunciar al reclutamiento forzoso, pueden ser perfectamente profesionales y seguir contando con conscriptos para funciones menores o, simplemente, para incentivar el reclutamiento remunerado. En el lado opuesto están quienes han abolido esta obligación antes de contar con unas fuerzas profesionales. En todo caso, lo que sí parece muy evidente es que la supresión del servicio militar obligatorio no es una decisión intrascendente: está suponiendo una completa redefinición del mapa militar europeo, en el que algunos países están mejorando su diferencial mientras otros están depreciándose en términos de fuerza operativa. Debemos desmentir, por lo tanto, que la supresión de la conscripción sea una decisión técnica; es una decisión política que tiene importantes consecuencias.

Partiendo de este supuesto, debemos dejar constancia de que no existe una única racionalidad en este complejo asunto. Son muchos los factores intervinientes. Entre ellos, además, los domésticos o propios de cada país parecen tener más peso que los internacionales o comunes al marco europeo. Ésta es al menos la conclusión que extraemos del análisis de las diez medidas que hemos incluido en este estudio. En un extremo de la banda estarían los casos de Holanda, Bélgica y, muy especialmente, Francia —incluimos el Reino Unido como caso de control- Como podemos comprobar en el cuadro resumen (tabla 11), todos ellos cumplen las condiciones de: a) armamento, equipamiento y capacitación militar suficientes; $b$ ) nivel satisfactorio de gasto militar; c) disponibilidad de fuerzas de acción rápida ajustadas en número y formato a la nueva prioridad de intervención militar; $d$ ) estructura de empleo consolidada y suficiente, y $e$ ) tamaño de fuerza correlativo al tamaño poblacional y a las aspiraciones de poder de las élites, eso que se suele expresar como «ocupar el lugar que nos corresponde».

Las opciones de Dinamarca, Noruega y Alemania demuestran que modelo de empleo y recluta forzosa no son realidades mutuamente excluyentes. Noruega sigue considerando la defensa territorial como una prioridad de primer orden y conserva la conscripción como parte de su esquema de movilización total. Dinamarca continúa con el mismo reclutamiento selectivo - muy cercano al modelo de empleo pero basado en la conscripción- que adoptó en los setenta, precisamente, para neutralizar la amenaza de una objeción de conciencia demasiado grande. Alemania es un caso peculiar: en los noventa ha elegido retomar el sistema de conscripción en vez de exclusivizar el modelo de empleo 
como su vecina Francia (Schmitz, 1994). Tres serían sus razones básicas: 1) es la opción más económica y ajustada al esfuerzo que acarrea su pacto de solidaridad con las gentes de la ex RDA; 2) la prestación sustitutoria se ha convertido en un elemento imprescindible para mantener los servicios del Estado del bienestar (Kuhlmann y Lippert 1993), y 3) las fuerzas armadas reclutan el $50 \%$ de su tropa de empleo entre los reclutas forzosos. El riesgo de este diseño es que el crecimiento de la objeción de conciencia o la presión política acaben forzando la supresión del servicio militar obligatorio y, con ello, esa prestación sustitutoria tan rentable.

\section{TABLA 11}

Variables que determinan la abolición de la conscripción en el momento actual

Fra. RU Hol. Bél. Din. Por. Nor. Ale. Ita. Esp.

\section{Razón de Estado}

Nuclearización y modernización tecno-

\begin{tabular}{|c|c|c|c|c|c|c|c|c|c|c|}
\hline lógica & ++ & ++ & + & + & & & + & + & & \\
\hline 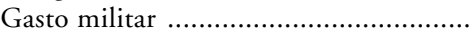 & ++ & ++ & + & + & & ++ & + & + & & \\
\hline Fuerzas de acción rápida ......................... & ++ & ++ & ++ & ++ & + & & + & ++ & ++ & \\
\hline 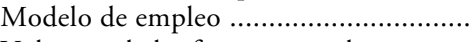 & ++ & ++ & ++ & ++ & + & + & & & & \\
\hline Volumen de las fuerzas armadas ............ & ++ & + & + & + & ++ & + & ++ & + & & \\
\hline \multicolumn{11}{|l|}{ Razón democrática } \\
\hline 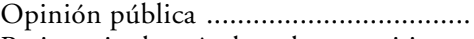 & + & & + & + & & & & & + & ++ \\
\hline \multirow{2}{*}{\multicolumn{11}{|c|}{$\begin{array}{l}\text { Resistencia al envío de reclutas a misiones } \\
\text { internacionales }\end{array}$}} \\
\hline & + & & + & + & & & & + & + & ++ \\
\hline Movilización en contra del reclutamiento .. & & & & & & & & & + & ++ \\
\hline 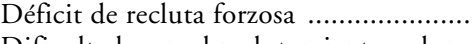 & & & & & & & & + & ++ & ++ \\
\hline $\begin{array}{l}\text { Dificultades en el reclutamiento volun- } \\
\text { tario }\end{array}$ & & + & & + & & & + & & ++ & ++ \\
\hline
\end{tabular}

Por fin, en el otro extremo de la banda encontramos a Italia y España. Ambos países han decidido el fin de la conscripción, pero no como resultado de una consolidación del modelo de empleo largamente anticipado e impulsado por las autoridades - tanto España como Italia dieron en 1987 sus primeros y muy tímidos pasos al respecto-, sino porque en los últimos años han concurrido, sobre todo en el caso de España: a) una opinión pública que se ha manifestado claramente en contra de la conscripción y $b$ ) en contra también del envío de reclutas forzosos a misiones internacionales; $c$ ) una movilización sustantiva en forma de desobediencia civil que ha contado con un apoyo social suficiente; d) consecuencia de todo ello, un crecimiento sostenido de la objeción de conciencia que ha superado el umbral de sostenibilidad del reclutamiento forzoso; y, por fin, $e$ ) dificultades graves en el reclutamiento voluntario. 
En suma, partiendo de la base de que existe un antagonismo cierto entre la razón de Estado y la razón democrática en relación con la política de la conscripción, y aun reconociendo que la presión de la razón democrática ha sido una clave fundamental a lo largo de los últimos treinta años para explicar la decisión actual de algunos gobiernos europeos de prescindir de esa prestación militar, comprobamos que en algunos casos la decisión final se corresponde básicamente con la razón de Estado; es decir, esta razón ha consolidado unas fuerzas armadas sobre la base del empleo antes de satisfacer la demanda original de la razón democrática de suprimir la conscripción. El ejemplo prototípico es Francia. Por el contrario, en otros casos ha sido la razón democrática la que ha impuesto esa supresión en unas condiciones desfavorables para los intereses de la razón de Estado. Puede incluso decirse que la razón democrática opera como una pinza en relación con la política militar: ha forzado la abolición de la conscripción pero niega su cooperación en la subsiguiente reestructuración de las fuerzas armadas. Es el caso de España. En definitiva, las decisiones de abolir la conscripción en Francia y España coinciden en el tiempo pero poco más; su lógica interna es radicalmente diferente, como también lo son las perspectivas de futuro de sus políticas de seguridad y defensa.

\section{REFERENCIAS BIBLIOGRÁFICAS}

Agirre, Xabier; Ajangiz, Rafael; Ibarra, Pedro, y Sainz de Rozas, Rafael (1998): La insumisión, un singular ciclo histórico de desobediencia civil, Madrid: Tecnos.

Agøy, Nils Ivar (1990): «The Norwegian Peace Movement and the Question of Conscientious Objection to Military Service, 1885-1922", en Towards a Comparative Analysis of Peace Movements, edición de Katsuya Kodama y Unto Vesa, Brookfield: Dartmouth, pp. 89-104.

AJANGIZ, Rafael (1992): «La opinión pública ante el servicio militar, la objeción de conciencia y la defensa militar», en Objeción e insumisión, claves ideológicas y sociales, edición de Pedro Ibarra, Madrid: Fundamentos, pp. 265-292.

- (2000): «Política militar y movimientos sociales: el fin de la conscripción en Europa», tesis doctoral en el área de Ciencia Política y de la Administración, Universidad del País Vasco.

Albesano, Sergio (1993): Storia dell'obiezione di coscienza in Italia, Treviso: Santi Quaranta.

Auvray, Michel (1983): Objecteurs, insoumis, déserteurs. Histoire des réfractaires en France, París: Stock.

Battistelli, Fabrizio (1997): "Servizio militare e servizio civile alla vigilia della riforma. Gli aspetti sociologici», Sistema Informativo Archivio Disarmo, 10 (3): 1-8.

BufFOTOT, Patrice (1997a): «Eviter la marginalisation», en La défense en Europe. Les adaptations de l'après-guerre froide, edición de Patrice Buffotot, París: La Documentation Française, pp. 183-187.

- (ed.) (1997b): La défense en Europe. Les adaptations de l'après-guerre froide, París: La Documentation Française.

- (1997c): "Les temps de réformes», en La défense en Europe. Les adaptations de l'après-guerre froide, edición de Patrice Buffotot, La Documentation Française, pp. 97-119.

BURK, James (1994): "Thinking Through the End of Cold War», en The Military in New Times. Adapting Armed Forces to a Turbulent World, edición de James Burk, Oxford: Westview Press, pp. 1-24.

Burstein, Paul (1991): «Policy Domains: Organization, Culture, and Policy Outcomes», Annual Review of Sociology, 17: 327-350. 
CARR, Fergus, e IfanTIS, Kostas (1996): NATO in the New European Order, Londres: MacMillan Press Ltd.

Cattelain, Jean-Pierre (1973): La objeción de conciencia, Barcelona: Oikos Tau.

Cohen, Elliot A. (1985): Citizen and Soldiers. The Dilemmas of Military Service, Londres: Cornell University Press.

Cortright, David, y WatTs, Max (1991): Left Face. Soldier Unions and Resistance Movements in Modern Armies, Wesport, CT: Greenwood Press.

Cosidó, Ignacio (1994): El gasto militar. El presupuesto de Defensa en España (1982-1992), Madrid: Eudema.

- (1996): «Factores económicos que condicionan la profesionalización», en La profesionalización en los ejércitos. Un cambio radical de mentalidad para un Estado moderno, edición de Martín Aleñar, Madrid: Fundación Cánovas del Castillo, pp. 137-162.

Chatfield, Charles (1995): «Ironies of Protest. Interpreting the American Anti-Vietnam War Movement», en Twentieth-Century Peace Movements: Successes and Failures, edición de Guido Grunewald y Peter van den Dungen, Lewiston: Edwin Mellen Press, pp. 199-208.

Chicken, Paule (1996): "Conscription Revisited», en France: Form the Cold War to the New World Order, edición de T. Chafer y B. Jenkins, Nueva York: St. Martin’s Press, pp. 93-103.

DANDEKer, Christopher (1994a): «A Farewell to Arms? The Military and the Nation-State in a Changing World", en The Military in New Times. Adapting Armed Forces to a Turbulent World, edición de James Burk, Oxford: Westview Press, pp. 117-139.

- (1994b): «New times for the military: some sociological remarks on the changing role and structure of the armed forces of the advanced societies", British Journal of Sociology, 45 (4): 637-654.

Della Porta, Donatella, y Diani, Mario (1997): I movimenti sociali, Roma: La Nuova Italia Scientifica.

Della Porta, Donatella, y Rucht, Dieter (1995): "Left-Libertarian Movements in Context: A Comparison of Italy and West Germany, 1965-1990", en The Politics of Social Protest. Comparative Perspectives on States and Social Movements, edición de J. Craig Jenkins y Bert Klandermans, Londres: UCL Press, pp. 229-272.

Dietz, Peter J., y Stone, J. F. (1975): "The British All-Volunteer Army», Armed Forces and Society, 1 (2): 159-190.

Doel, Theo van den (1994): "A Review of Dutch Defense Policy: Challenges and Risks", en Reestructuring Armed Forces in East and West, edición de Jan Geert Siccama y Theo van den Doel, Oxford: Westview Press, pp. 57-67.

Doorn, Jacques van (1975): «The Decline of the Mass Army in the West. General Reflections», Armed Forces and Society, 1 (2): 147-157.

- (1976): "The Military and the Crisis of Legitimacy», en The Military and the Problem of Legitimacy, edición de Gwyn Harries-Jenkins y Jacques van Doorn, Londres: Sage, pp. 17-40.

Dorman, Andrew M., y Treacher, Adrian (1995): European Security. An Introduction to Security Issues in Post-Cold War Europe, Cambridge: Dartmouth Publishing Company.

Downes, Cathy (1991): "Gran Bretaña», en Lo Militar: ¿Más que una Profesión?, edición de Charles C. Moskos y Frank R. Wood, Madrid: Ministerio de Defensa, pp. 201-228.

DuYvendak, Jan Willem (1995): The Power of Politics. New Social Movements in France, Boulder, CO: Westview Press.

Estrella, Rafael (1993): «Military Trends Within the Atlantic Alliance Sub-Committee on the Future of the Armed Forces», Informe interno de la OTAN AK76 DSC/AF(93)1.

FARNÉ, Roberto, y PROTTI, Giulio (1996): Il soldato e l'obiettore. Una ricerca sul servizio militare e civile, Roma: Libreria Ateneo Salesiano.

Forrest, Alan (1989): Conscripts and Deserters. The Army and French Society during the Revolution and Empire, Oxford: Oxford University Press.

Giugni, Marco; McAdam, Doug, y Tilly, Charles (eds.) (1999): How Social Movements Matter. Theoretical and Comparative Studies on the Consequences of Social Movements, Minneapolis: University of Minnesota Press. 
Gleditsch, Nils Petter (1990): "The Rise and Decline of the New Peace Movement», en Towards a Comparative Analysis of Peace Movements, edición de Katsuya Kodama y Unto Vesa, Brookfield: Dartmouth, pp. 73-88.

Harries-Jenkins, Gwyn (ed.) (1982): Armed Forces and the Welfare Societies: Challenges in the 1980s, Londres: MacMillan Press.

Hilsman, Roger; Gaughram, Laura, y Weitsman, Patricia A. (1993): The Politics of Policy Making in Defense and Foreign Affairs. Conceptual Models and Bureaucratic Politics, Englewood Cliffs: Prentice Hall.

HorEMAN, Bart, y STOLWIJK, Marc (1998): Refusing to bear arms: a world survey of conscription and conscientious objection to military service. America, former USSR, Asia and Australia, Middle East, Londres: War Resisters' International.

Horeman, Bart; STOLWIJK, Marc, y LuCCIONI, Anton (1997): Refusing to bear arms: a world survey of conscription and conscientious objection to military service. Part 1: Europe, Londres: War Resisters' International.

HuesCa GONZÁlez, Ana María (1994): «La actitud de los españoles ante la multinacionalidad de la Defensa", en Aportación sociológica de la sociedad española a la defensa nacional, edición del Instituto Español de Estudios Estratégicos, Madrid: Ministerio de Defensa, pp. 137-154.

IBARRA, Pedro (ed.) (1992): Objeción e insumisión, claves ideológicas y sociales, Madrid: Fundamentos.

INGLEHART, Ronald (1976): "Changing Values and Attitudes toward Military Service among the American Public», en The Social Psychology of Military Service, edición de Nancy L. Goldman y David R. Segal, Londres: Sage, pp. 255-278.

- (1977): The Silent Revolution. Changing Values and Political Styles Among Western Publics, Princeton y Oxford: Princeton University Press.

Janowitz, Morris (1971): «Prologue to the 2nd edition», en The Professional Soldier, Nueva York: The Free Press.

- (1972): "The Decline of the Mass Army», Military Review, 52 (2): 10-16.

- (1975): «U.S. Forces and the Zero Draft», en Military Conflict. Essays in the Institutional Analysis of War and Peace, edición de Morris Janowitz, Londres: Sage, pp. 239-283.

- (1990): El soldado profesional, Madrid: Ministerio de Defensa.

JANOWITZ, Morris, y Moskos, Charles C. (1979): "Five Years of the All-Volunteer Force: 19731978", Armed Forces and Society, 5 (2): 171-217.

Kelleher, Catherine McArdle (1978): «Mass Armies in the 1970s. The Debate in Western Europe", Armed Forces and Society, 5 (1): 3-29.

Kiljunen, Kimmo, y VäÄnÄnen, Jouko (eds.) (1987): Youth and Conscription, Jyväskylässä: International Peace Bureau, War Resisters' International, Peace Union of Finland, Union of Conscientious Objectors in Finland.

Klandermans, Bert (ed.) (1991): Peace Movements in Western Europe and the United States, Londres: Jai Press.

Koopmans, Ruud (1995): Democracy from Below. New Social Movements and the Political System in West Germany, Boulder, CO: Westview Press.

Kriesi, Hanspeter; KoOpmans, Ruud; DuyvendaK, Jan Willem, y GiUgni, Marco G. (1995): New Social Movements in Western Europe. A Comparative Analysis, Minneapolis: University of Minnesota Press.

Kuhlmann, Jürgen, y LipPerT, Ekkehard (1993): «The Federal Republic of Germany: Conscientious Objection as Social Welfare», en The New Conscientious Objection. From Sacred to Secular Resistance, edición de Charles C. Moskos y John W. Chambers, Oxford: Oxford University Press, pp. 98-105.

Levi, Margaret (1997): Consent, Dissent, and Patriotism, Cambridge: Cambridge University Press.

LuCASSEN, Jan, y ZÜrCHER, Erik Jan (1998): "Conscription as Military Labour: The Historical Context», International Review of Social History, 43: 405-419.

LYONS, Matthew (1999): "The Grassroots Movement in Germany, 1972-1985», en Nonviolent Social Movements. A Geographical Perspective, edición de Stephen Zunes, Lester R. Kurtz y Sarah Beth Asher, Oxford: Blackwell, pp. 81-95. 
MANFRASS-SIRJACQUES, Françoise (1997): «Entre restructuration interne et normalisation internationale», en La défense en Europe. Les adaptations de l'après-guerre froide, edición de Patrice Buffotot, París: La Documentation Française, pp. 15-33.

MAnigart, Philippe, y MARLier, Eric (1994): «La opinión pública europea sobre el futuro de su seguridad», Cuenta y Razón del Pensamiento Actual, 85: 61-68.

MARTin, Michel L. (1977): "Conscription and the Decline of the Mass Army in France, 19601975", Armed Forces and Society, 3 (3): 355-406.

- (1993): «France: A Statue but No Objectors», en The New Conscientious Objection. From Sacred to Secular Resistance, edición de Charles C. Moskos y John W. Chambers, Oxford: Oxford University Press, pp. 80-97.

Massarrat, Mosen, y Betz, Paul (eds.) (1998): For a Military-Free Peace Policy. European Peace Congress Osnabrück 1998, Münster: Agenda Verlag.

McKennA, J. Justin (1997): «Towards the Army of the Future: Domestic Politics and the End of Conscription in France», West European Politics, 20 (4): 125-145.

Mellors, Colin, y MCKean, John (1982): «Confronting the State: Conscientious Objection in Western Europe», Bulletin of Peace Proposals, 13 (3): 227-239.

- (1984): «The Politics of Conscription in Western Europe», West European Politics, 7 (3): 25-42.

Meulen, Jan van der, y Manigart, Philippe (1997): «Zero Draft in the Low Countries: The Final Shift to the All-volunteer Force», Armed Forces and Society, 24 (2): 315-332.

Moskos, Charles C., y Chambers, John W. (eds.) (1993): The New Conscientious Objection. From Sacred to Secular Resistance, Oxford: Oxford University Press.

Pagnucco, Ron, y Smith, Jackie (1993): «The Peace Movement and the Formulation of U.S. Foreign Policy", Peace \& Change, 18 (2): 157-181.

Quaker Council For European AfFaIrs (1984): Conscientious Objection to Military Service in Europe, Bruselas: Council of Europe.

RAMOS, Ramón (1987): Actitudes y opiniones de los españoles ante las relaciones internacionales, Madrid: Centro de Investigaciones Sociológicas.

Rochon, Thomas R. (1988): Mobilizing for Peace. The Antinuclear Movements in Western Europe, Londres: Adamantine Press Ltd.

Rosenau, James N. (1994): "Armed Force and Armed Forces in a Turbulent World», en The Military in New Times. Adapting Armed Forces to a Turbulent World, edición de James Burk, Oxford: Westview Press, pp. 25-61

SALES, Nuria (1974): Sobre esclavos, reclutas y mercaderes de quintos, Barcelona: Ariel Quincenal.

Schmitz, Peter N. (1994): «Adapting the German Armed Forces to the New Security Situation", en Reestructuring Armed Forces in East and West, edición de Jan Geert Siccama y Theo van den Doel, Oxford: Westview Press, pp. 39-50.

SeEgers, Annette (1993): «South Africa: From Laager to Anti-Apartheid», en The New Conscientious Objection. From Sacred to Secular Resistance, edición de Charles C. Moskos y John W. Chambers, Oxford: Oxford University Press, pp. 127-134.

SHAw, Martin (1991): Post-Military Society, Oxford: Polity Press.

SMET, Luc de (1990): «The Belgian Peace Movement Polled», en Towards a Comparative Analysis of Peace Movements, edición de Katsuya Kodama y Unto Vesa, Brookfield: Dartmouth, pp. 235-253.

Sørensen, Henning (2000): "Conscription in Scandinavia During the Last Quarter Century: Developments and Arguments», Armed Forces and Society, 26 (2): 313-334.

ThuysbaerT, George (1994): "Restructuring the Armed Forces of Belgium», en Reestructuring Armed Forces in East and West, edición de Jan Geert Siccama y Theo van den Doel, Oxford: Westview Press, pp. 51-56.

Useem, Michael (1973): Conscription, Protest, and Social Conflict. The Life and Death of a Draft Resistance Movement, Nueva York: John Wiley \& Sons.

War Resisters International (1990): Conscription and Conscientious Objection: Profile of the Situation in Different Countries, Londres: War Resisters' International.

Weber, Max (1964): Economía y sociedad, México: Fondo de Cultura Económica.

YounG, Nigel (1984): «War Resistance, State and Society», en War, State and Society, edición de Martin Shaw, Londres: MacMillan Press, pp. 95-116. 


\begin{abstract}
The latest changes that have occurred in Europe regarding conscription are analysed starting from the observation of a long and extensive process of decline of mass armies. Ten indicators of that crisis are presented and analysed to reach the conclusion that civil society, referred to here as democratic reason, has exerted a much greater influence than is usually acknowledged in the recent decision of several European governments to abolish this duty. In the majority of the cases studied, even despite the fact that governments have been able to establish norms for this change according to their strategic priorities, the end of conscription is, in fact, a delayed consequence of the mobilisation of such democratic reason. In others, such as the case of Italy and, more particularly, Spain, this mobilisation has forced a hasty and problematical change of government plans in this respect. In short, the continuity of this obligatory service in some of the countries around us makes it possible to understand the end of conscription as an optional decision and not a compulsory consequence of the choice or consolidation of the model to be used in the armed forces.
\end{abstract}

